\title{
How Spherical Are Gaseous Low Charged Dendrimer Ions: A Molecular Dynamics / Ion Mobility Study?
}

Fabrice Saintmont ${ }^{\mathrm{a}, \mathrm{b}}$, Julien De Winter ${ }^{\mathrm{a}}$, Fabien Chirot $^{\mathrm{c}}$, Emilie Halin $^{\mathrm{a}}$, Philippe Dugourd ${ }^{\mathrm{d}}$, Patrick Brocorens $^{\mathrm{b}}$, Pascal Gerbaux ${ }^{\mathrm{a}^{*}}$

\footnotetext{
${ }^{a}$ Organic Synthesis \& Mass Spectrometry Laboratory, Interdisciplinary Center for Mass Spectrometry (CISMa), Center of Innovation and Research in Materials and Polymers (CIRMAP), University of Mons - UMONS, 23 Place du Parc, 7000 Mons, Belgium

${ }^{\mathrm{b}}$ Laboratory for Chemistry of Novel Materials, Center of Innovation and Research in Materials and Polymers, Research Institute for Science and Engineering of Materials, University of Mons - UMONS, 23 Place du Parc, 7000 Mons, Belgium

${ }^{c}$ Université Lyon, Université Claude Bernard Lyon 1, ENS de Lyon, CNRS, Institut des Sciences Analytiques, UMR 5280, 5 rue de la Doua, F-69100, Villeurbanne, France

d Université Lyon, Université Claude Bernard Lyon 1, CNRS, Institut Lumière Matière, F-69622, Lyon, France

${ }^{*}$ Corresponding Author
}

Supporting information 


\section{PAMAM}

Table S1: Comparison between ${ }^{\mathrm{TW}} \mathrm{CCS}_{\mathrm{N} 2 \rightarrow \mathrm{He}}$ and ${ }^{\mathrm{DT}} \mathrm{CCS}_{\mathrm{He}}$ for EDA and CYS PAMAM

\begin{tabular}{|c|c|c|c|c|c|c|c|}
\hline \multicolumn{8}{|c|}{ EDA PAMAM } \\
\hline $\mathrm{G}_{\mathrm{x}}$ & charge & $m / z$ & ${ }^{T W} C C S_{N 2 \rightarrow H e}\left(\AA^{2}\right)$ & ${ }^{\mathrm{DT}} \mathrm{CCS}_{\mathrm{He}}\left(\AA^{2}\right)$ & $\Delta \operatorname{CCS}(\%)^{a}$ & $\begin{array}{l}{ }^{T W} C C S_{N 2 \rightarrow H e}\left(\AA^{2}\right) \\
\text { single calibration }\end{array}$ & $\Delta \operatorname{CCS}(\%)^{\mathrm{b}}$ \\
\hline \multirow{2}{*}{ G0 } & +1 & 517 & $155 \pm 2$ & 161 & +3.1 & 166 & -3.3 \\
\hline & +2 & 259 & $154 \pm 3$ & 159 & +3.1 & 181 & -12.1 \\
\hline \multirow{2}{*}{ G1 } & +2 & 715 & $316 \pm 2$ & 314 & -1.1 & 309 & +0.9 \\
\hline & +3 & 477 & $350 \pm 1$ & 335 & -5.4 & 334 & -1.0 \\
\hline \multirow{3}{*}{$\mathrm{G} 2$} & +3 & 1086 & $539 \pm 2$ & 542 & +0.6 & 531 & +2.1 \\
\hline & +4 & 818 & $586 \pm 2$ & 598 & +2.0 & 571 & +4.7 \\
\hline & +5 & 652 & $662 \pm 3$ & 657 & -0.7 & 636 & +3.2 \\
\hline \multicolumn{8}{|c|}{ CYS PAMAM } \\
\hline $\mathrm{G}_{\mathrm{x}}$ & charge & $m / z$ & ${ }^{T W} C C S_{N 2 \rightarrow H e}\left(\AA^{2}\right)$ & ${ }^{\mathrm{DT}} \mathrm{CCS}_{\mathrm{He}}\left(\AA^{2}\right)$ & $\Delta \operatorname{CCS}(\%)^{a}$ & $\begin{array}{l}{ }^{T W} C C S_{N 2 \rightarrow H e}\left(\AA^{2}\right) \\
\text { single calibration }\end{array}$ & $\Delta \operatorname{CCS}(\%)^{\mathrm{b}}$ \\
\hline \multirow{2}{*}{ G0 } & +1 & 609 & $169 \pm 2$ & 169 & -0.6 & 179 & -5.6 \\
\hline & +2 & 305 & $177 \pm 3$ & 170 & -5.5 & 196 & -13.1 \\
\hline \multirow{2}{*}{ G1 } & +2 & 762 & $327 \pm 2$ & 320 & -2.0 & 320 & -0.2 \\
\hline & +3 & 508 & $368 \pm 1$ & 343 & -6.7 & 353 & -2.7 \\
\hline \multirow{4}{*}{ G2 } & +3 & 1116 & $546 \pm 2$ & 550 & +0.7 & 538 & +2.2 \\
\hline & +4 & 838 & $605 \pm 1$ & 612 & +1.1 & 591 & +3.6 \\
\hline & +5 & 671 & $680 \pm 3$ & 679 & -0.2 & 661 & +2.7 \\
\hline & +6 & 559 & $759 \pm 3$ & 773 & +1.8 & 726 & +6.5 \\
\hline \multirow{4}{*}{ G3 } & +4 & 1751 & $864 \pm 12$ & 864 & -0.1 & 849 & +1.8 \\
\hline & +5 & 1401 & $901 \pm 14$ & 925 & +2.7 & 880 & +5.1 \\
\hline & +6 & 1168 & $1013 \pm 14$ & 1046 & +3.3 & 982 & +6.5 \\
\hline & +7 & 1001 & $1101 \pm 9$ & 1144 & +3.9 & 1076 & +6.3 \\
\hline
\end{tabular}




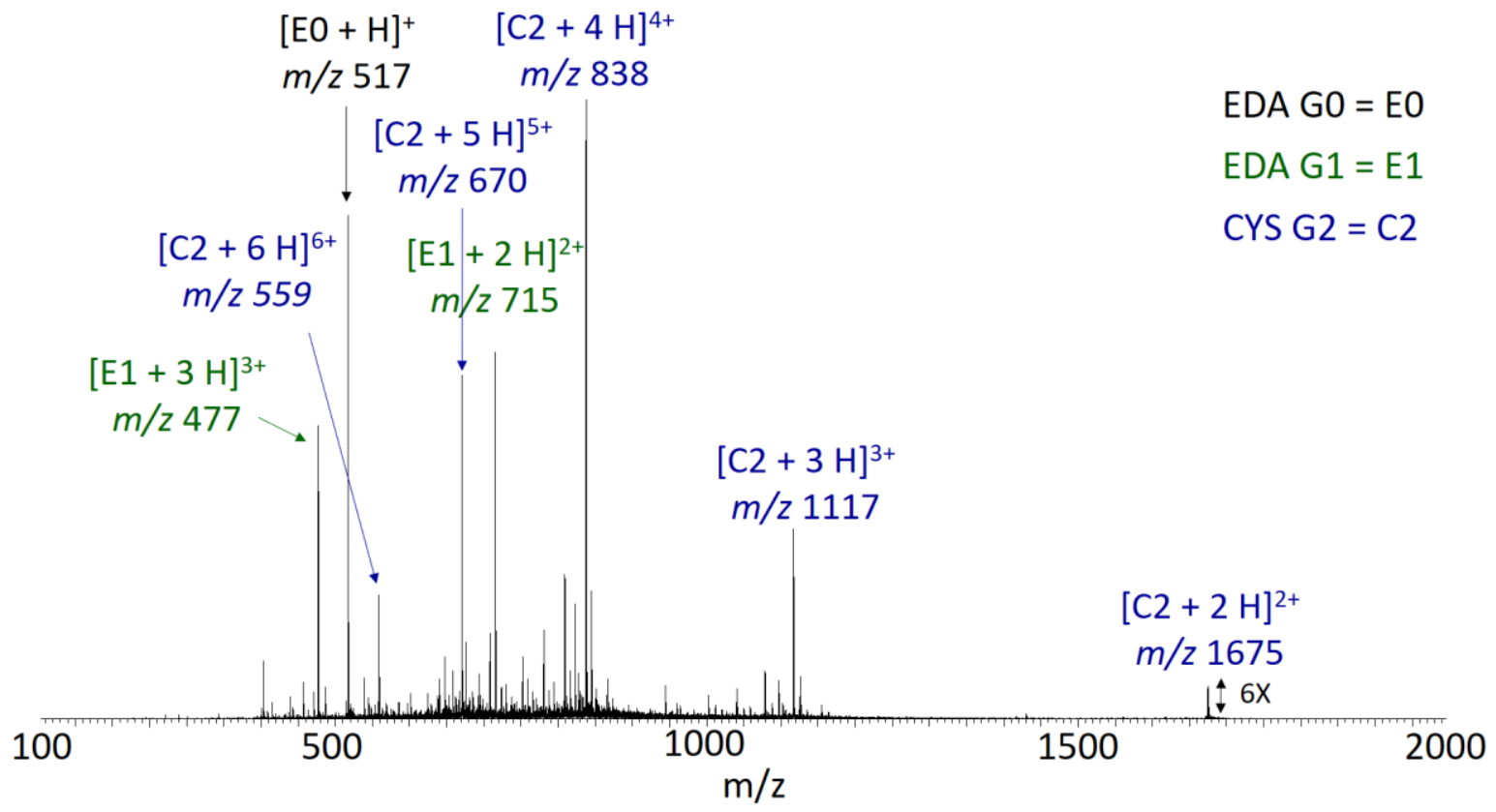

Figure S1: ESI(+)-MS spectrum of CYS PAMAM G2 dendrimer (C2). EDA PAMAM G1 (E1) and G0 (E0) are also present as a synthesis impurity.

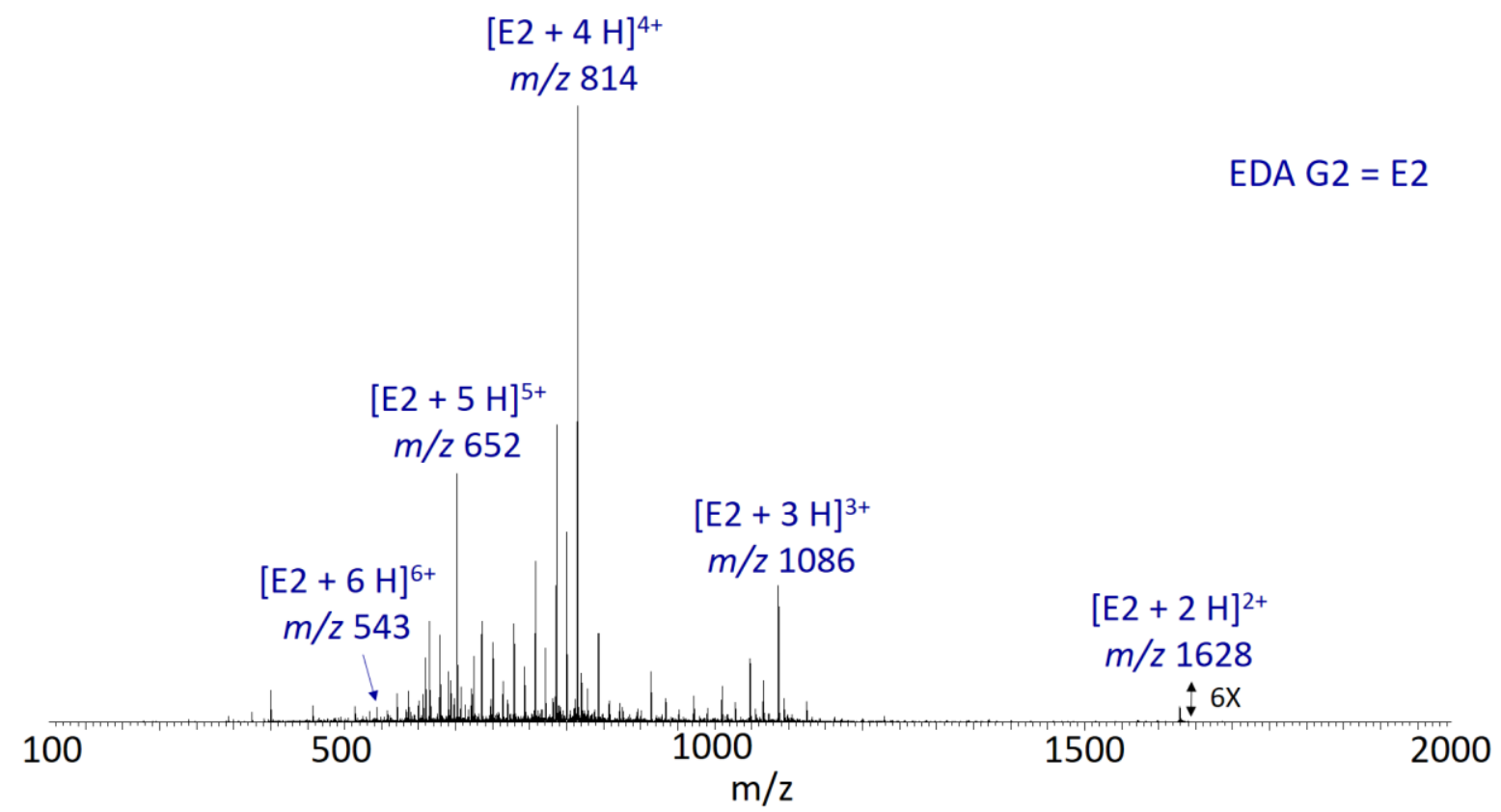

Figure S2: ESI(+)-MS spectrum of EDA PAMAM G2 dendrimer (E2). Peaks at lower m/z are typical from molecular loop ($60 \mathrm{u})$ and missing $\operatorname{arm}(-114 \mathrm{u})^{1}$. 


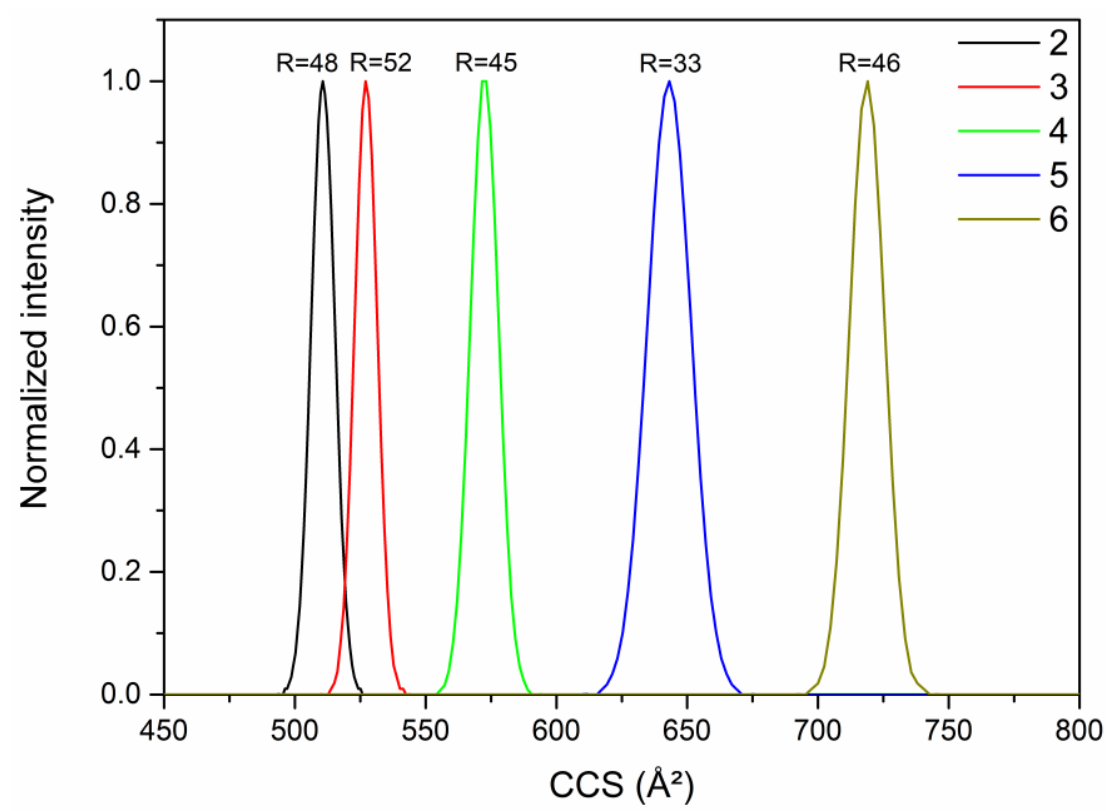

Figure S3: Evolution of CCS distribution with the number of charges (2+ to 6+) for EDA G2. The CCS resolution of each peak is indicated.

Table S2: Experimental and theoretical CCS of PAMAM ions.

\begin{tabular}{|c|c|c|c|c|c|}
\hline \multicolumn{6}{|c|}{ EDA PAMAM } \\
\hline $\mathrm{G}_{\mathrm{x}}$ & charge & $\mathrm{m} / \mathrm{z}$ & ${ }^{\mathrm{TW}} \mathrm{CCS}_{\mathrm{N} 2 \rightarrow \mathrm{He}}\left(\AA^{2}\right)$ & ${ }^{\mathrm{TM}} \mathrm{CCS}_{\mathrm{He}}\left(\AA^{2}\right)$ & $\Delta \operatorname{CCS}(\%)^{\mathrm{a}}$ \\
\hline \multirow{2}{*}{ G0 } & +1 & 517 & $155 \pm 2$ & $145 \pm 2$ & -6.5 \\
\hline & +2 & 259 & $154 \pm 3$ & $155 \pm 1$ & +0.4 \\
\hline \multirow{4}{*}{ G1 } & +1 & 1430 & $308 \pm 2$ & $279 \pm 3$ & -9.5 \\
\hline & +2 & 715 & $316 \pm 2$ & $292 \pm 3$ & -7.6 \\
\hline & +3 & 477 & $350 \pm 1$ & $341 \pm 5$ & -2.7 \\
\hline & +4 & 358 & $417 \pm 1$ & $366 \pm 4$ & -12.2 \\
\hline \multirow{5}{*}{ G2 } & +2 & 1629 & $521 \pm 2$ & $505 \pm 6$ & -3.1 \\
\hline & +3 & 1086 & $539 \pm 2$ & $519 \pm 6$ & -3.6 \\
\hline & +4 & 818 & $586 \pm 3$ & $557 \pm 6$ & -4.9 \\
\hline & +5 & 652 & $662 \pm 1$ & $625 \pm 8$ & -5.5 \\
\hline & +6 & 544 & $738 \pm 1$ & $722 \pm 7$ & -2.3 \\
\hline \multirow{4}{*}{ G3 } & +4 & 1728 & $847 \pm 7$ & $843 \pm 7$ & -0.4 \\
\hline & +5 & 1383 & $883 \pm 8$ & $908 \pm 9$ & +2.8 \\
\hline & +6 & 1152 & $967 \pm 6$ & $976 \pm 9$ & +1.0 \\
\hline & +7 & 988 & $1054 \pm 8$ & $1052 \pm 8$ & -0.2 \\
\hline \multicolumn{6}{|c|}{ CYS PAMAM } \\
\hline $\mathrm{G}_{\mathrm{x}}$ & charge & $\mathrm{m} / \mathrm{z}$ & ${ }^{\mathrm{TW}} \mathrm{CCS}_{\mathrm{N} 2 \rightarrow \mathrm{He}}\left(\AA^{2}\right)$ & ${ }^{\mathrm{TM}} \mathrm{CCS}_{\mathrm{He}}\left(\AA^{2}\right)$ & $\Delta \operatorname{CCS}(\%)$ \\
\hline G0 & +1 & 609 & $169 \pm 2$ & $162 \pm 2$ & -4.2 \\
\hline
\end{tabular}




\begin{tabular}{|c|c|c|c|c|c|}
\hline & +2 & 305 & $177 \pm 3$ & $168 \pm 2$ & -4.9 \\
\hline \multirow{4}{*}{ G1 } & +1 & 1522 & $324 \pm 2$ & $289 \pm 3$ & -10.7 \\
\hline & +2 & 762 & $327 \pm 2$ & $305 \pm 3$ & -6.7 \\
\hline & +3 & 508 & $368 \pm 1$ & $357 \pm 5$ & -3.0 \\
\hline & +4 & 381 & $432 \pm 2$ & $417 \pm 5$ & -3.4 \\
\hline \multirow{5}{*}{ G2 } & +2 & 1675 & $529 \pm 2$ & $521 \pm 5$ & -1.5 \\
\hline & +3 & 1116 & $546 \pm 2$ & $568 \pm 5$ & +4.0 \\
\hline & +4 & 838 & $605 \pm 1$ & $610 \pm 8$ & +0.8 \\
\hline & +5 & 671 & $680 \pm 3$ & $659 \pm 6$ & -3.2 \\
\hline & +6 & 559 & $759 \pm 3$ & $698 \pm 8$ & -8.0 \\
\hline \multirow{4}{*}{ G3 } & +4 & 1751 & $864 \pm 12$ & $841 \pm 8$ & -2.8 \\
\hline & +5 & 1401 & $901 \pm 14$ & $895 \pm 9$ & -0.7 \\
\hline & +6 & 1168 & $1013 \pm 14$ & $1046 \pm 12$ & +3.3 \\
\hline & +7 & 1001 & $1101 \pm 19$ & $1103 \pm 8$ & +0.2 \\
\hline
\end{tabular}
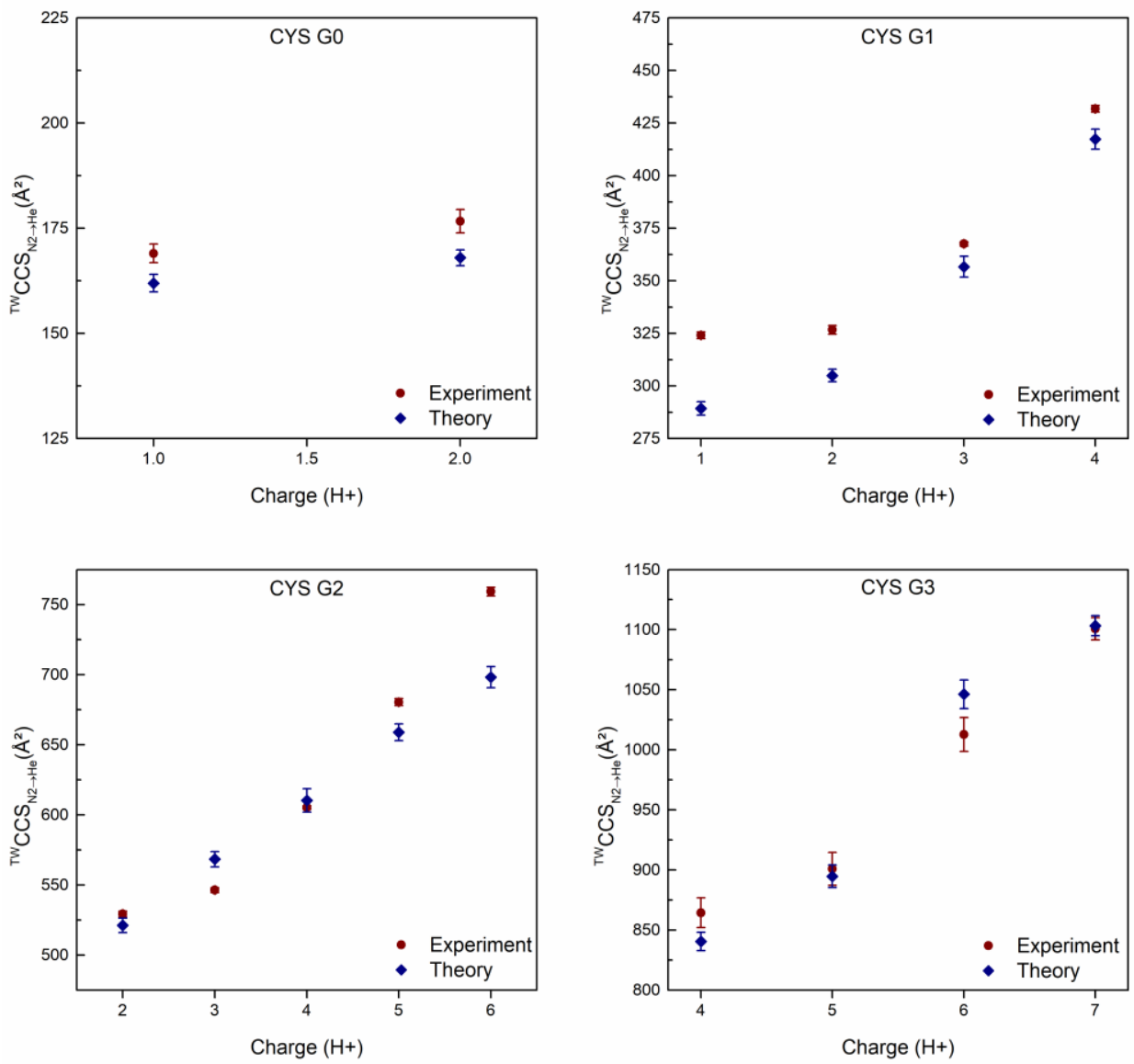

Figure S4: Comparison between experimental (red circle) and theoretical (blue diamond) CCS for CYS PAMAM G0 to G3. Error bars represent the standard deviation on $5(\mathrm{G} 0)$ or 3 (G1 to G3) experimental measurements, and on 200 theoretical structures, respectively. 


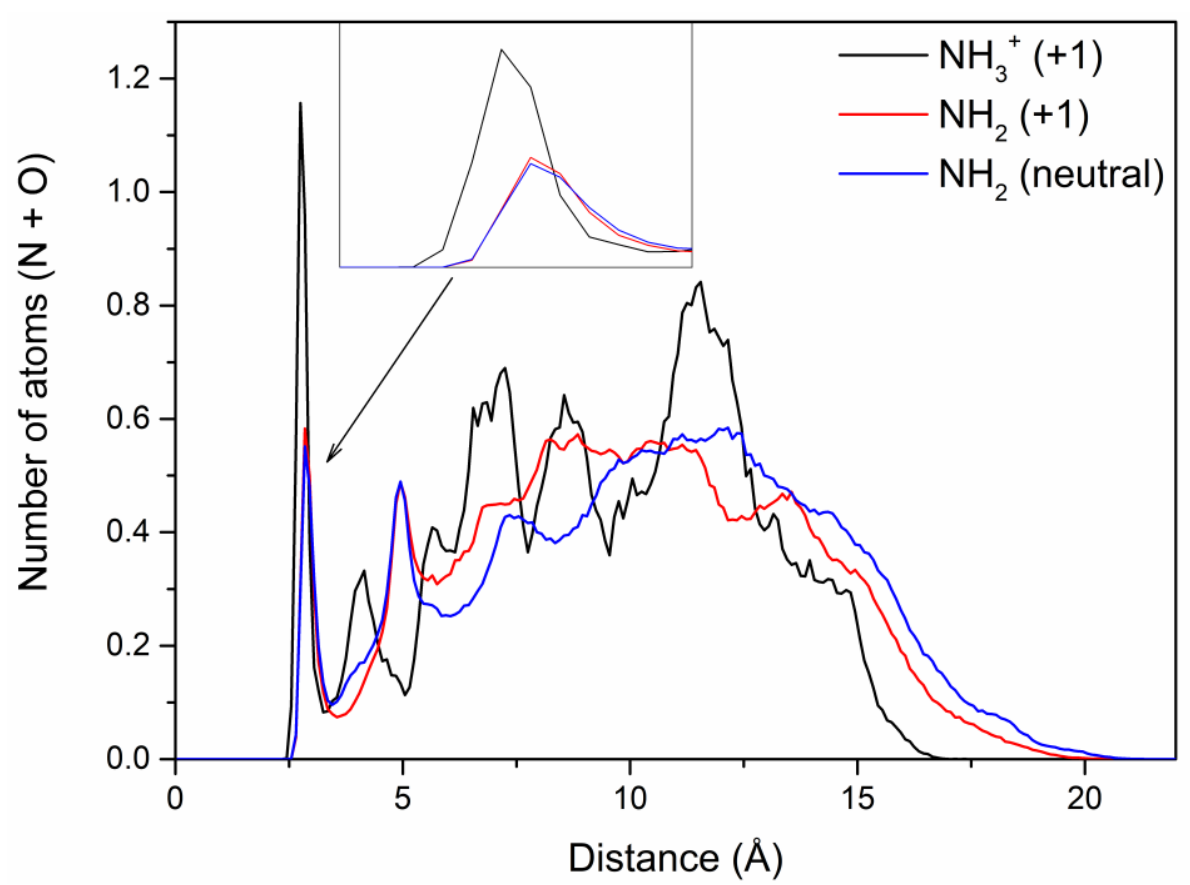

Figure S5: Number of oxygen atoms and amine nitrogen atoms found in concentric shells $0.1 \AA$ thick, as a function of the distance from terminal amine nitrogens in EDA G2 neutral and +1 . For the neutral, the curve is the average over all the terminal amines (blue). For the +1 , the averages over all the neutral amines (red) and the protonated amine (black) are separated. A zoom between 2.2 and $3.4 \AA$ is in insert.

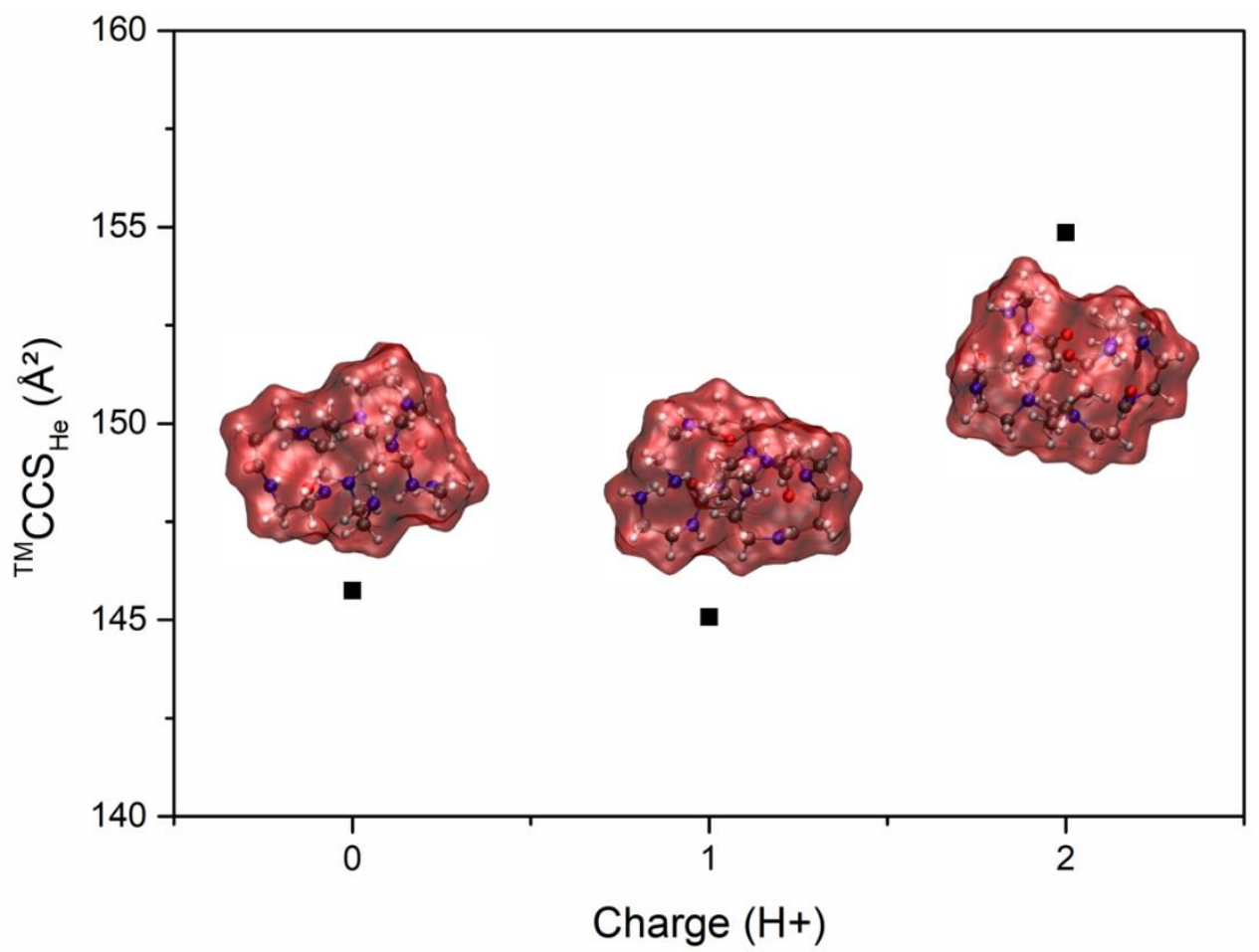

Figure S6: Evolution of the ${ }^{\mathrm{TM}} \mathrm{CCS}_{\mathrm{He}}$ for EDA PAMAM G0 from 0 to 2 charges. For each charge state, the structure is represented with the vdW surface in red. 


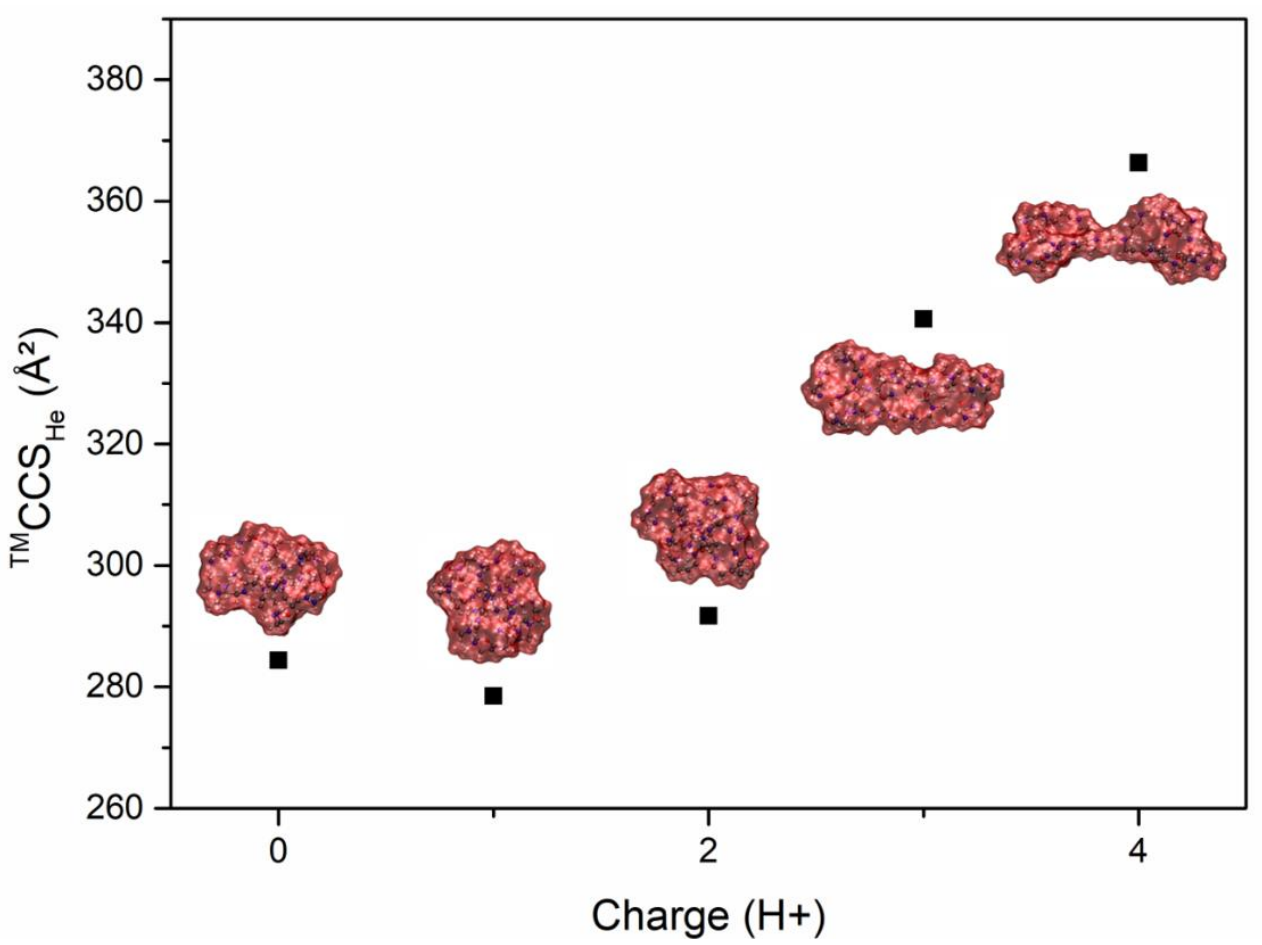

Figure S7: Evolution of the ${ }^{\mathrm{TM}} \mathrm{CCS}_{\mathrm{He}}$ for EDA PAMAM G1 from 0 to 4 charges. For each charge state, the structure is represented with the vdW surface in red.

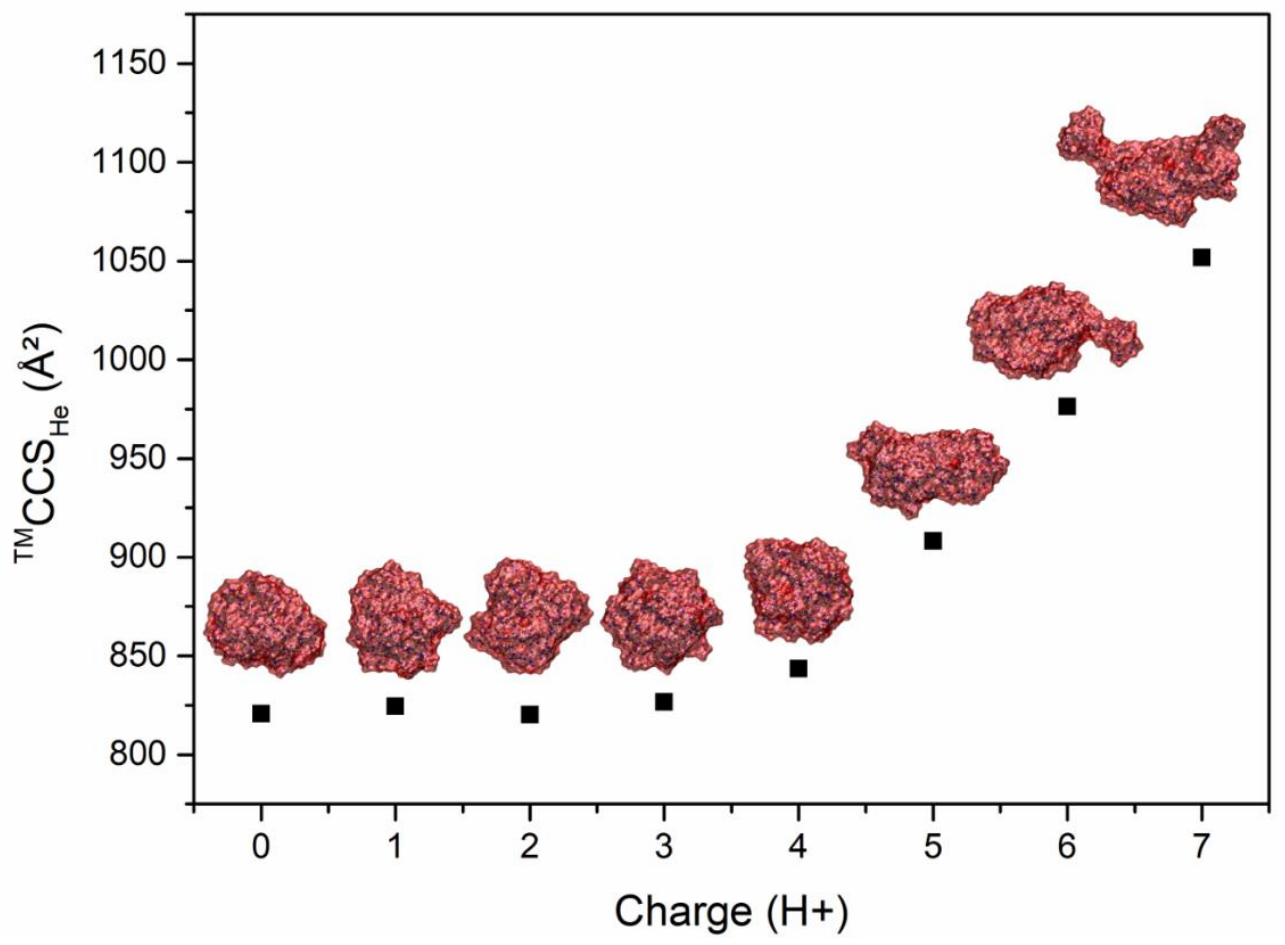

Figure S8: Evolution of the ${ }^{\mathrm{TM}} \mathrm{CCS}_{\mathrm{He}}$ for EDA PAMAM G3 from 0 to 7 charges. For each charge state, the structure is represented with the vdW surface in red. 


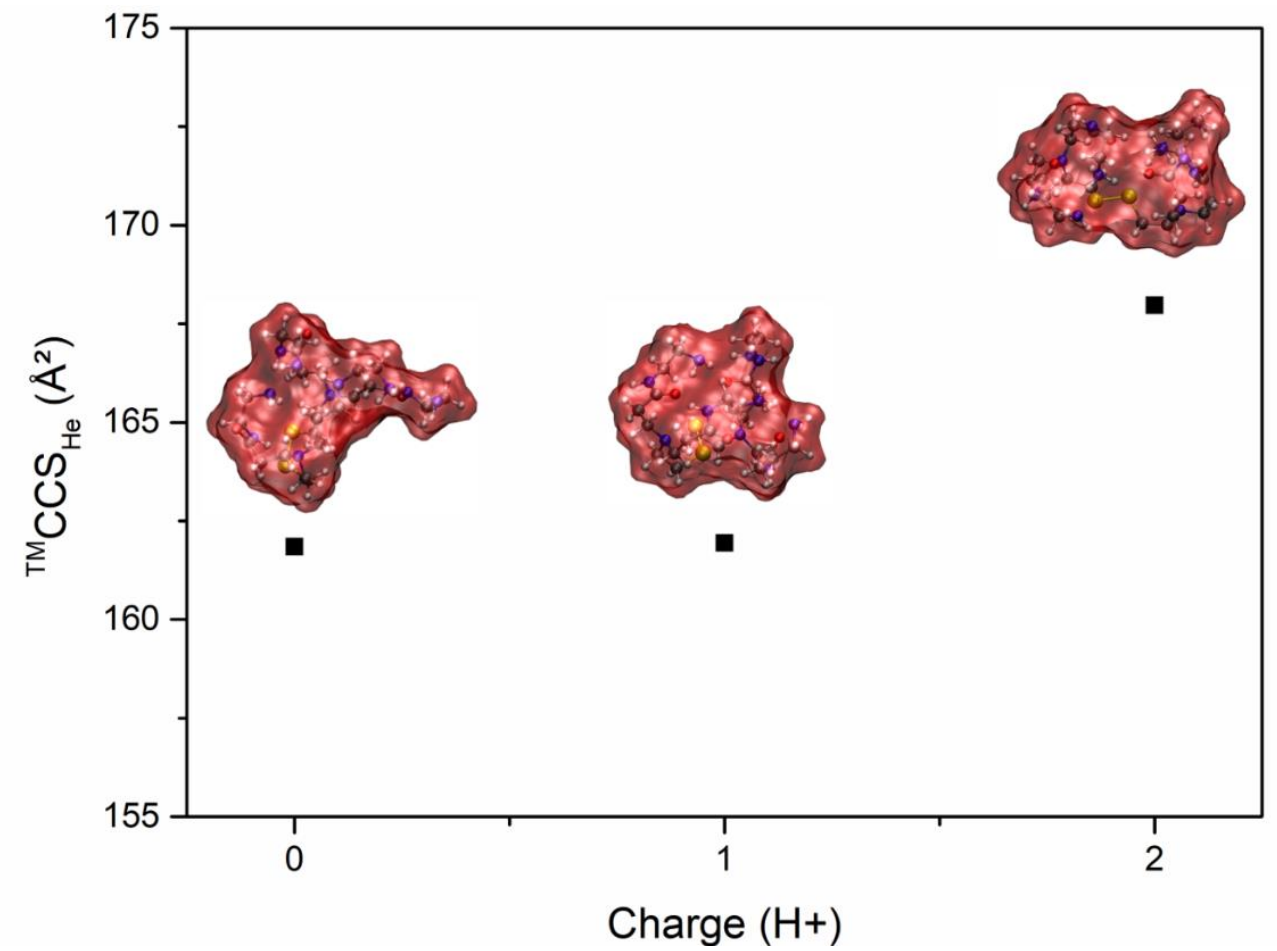

Figure S9: Evolution of the ${ }^{\mathrm{TM}} \mathrm{CCS}_{\mathrm{He}}$ for CYS PAMAM G0 from 0 to 2 charges. For each charge state, the structure is represented with the vdW surface in red.

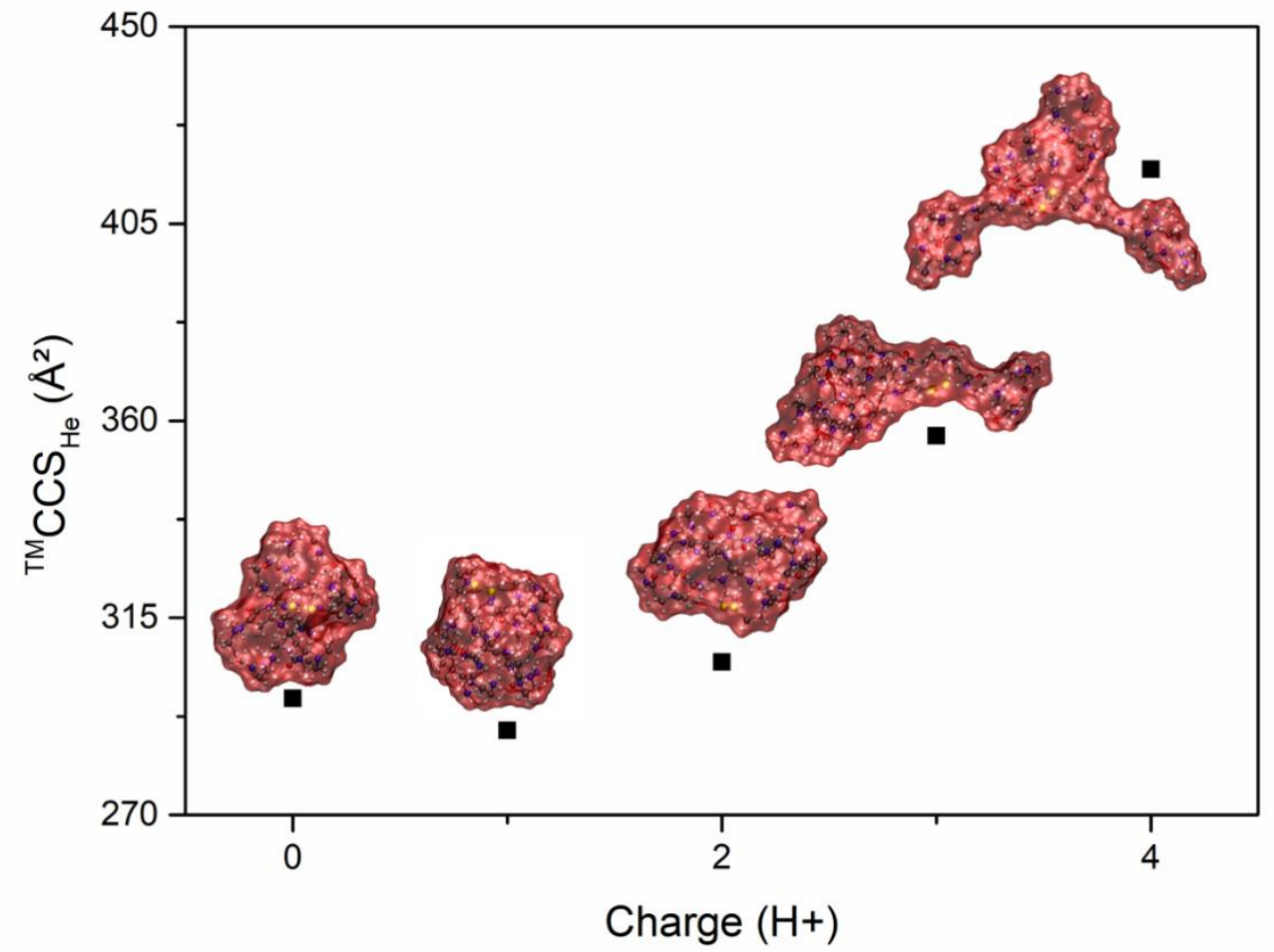

Figure S10: Evolution of the ${ }^{\mathrm{TM}} \mathrm{CCS}_{\mathrm{He}}$ for CYS PAMAM G1 from 0 to 4 charges. For each charge state, the structure is represented with the vdW surface in red. 


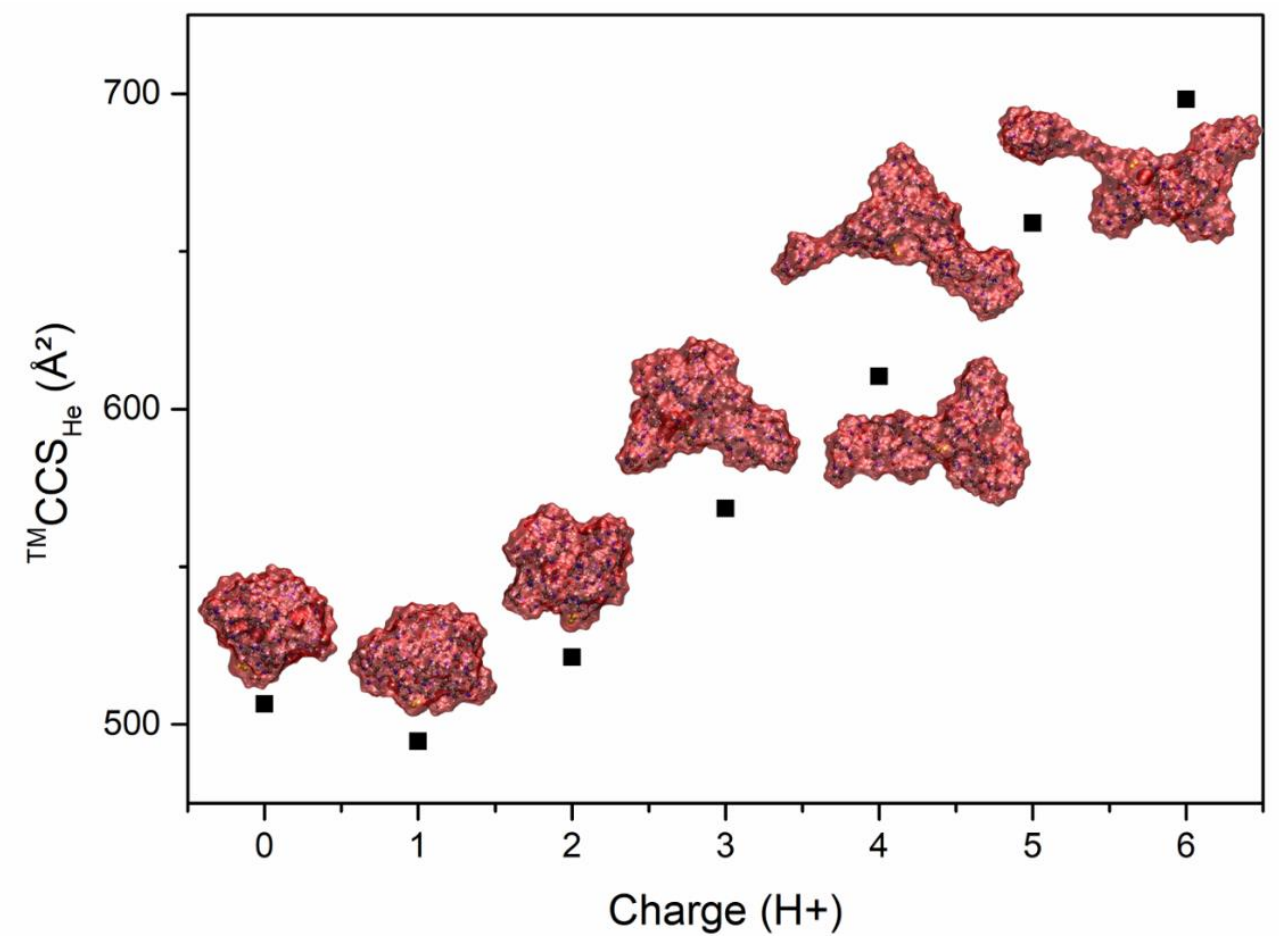

Figure S11: Evolution of the ${ }^{\mathrm{TM} C C S}$ He for CYS PAMAM G2 from 0 to 6 charges. For each charge state, the structure is represented with the vdW surface in red.

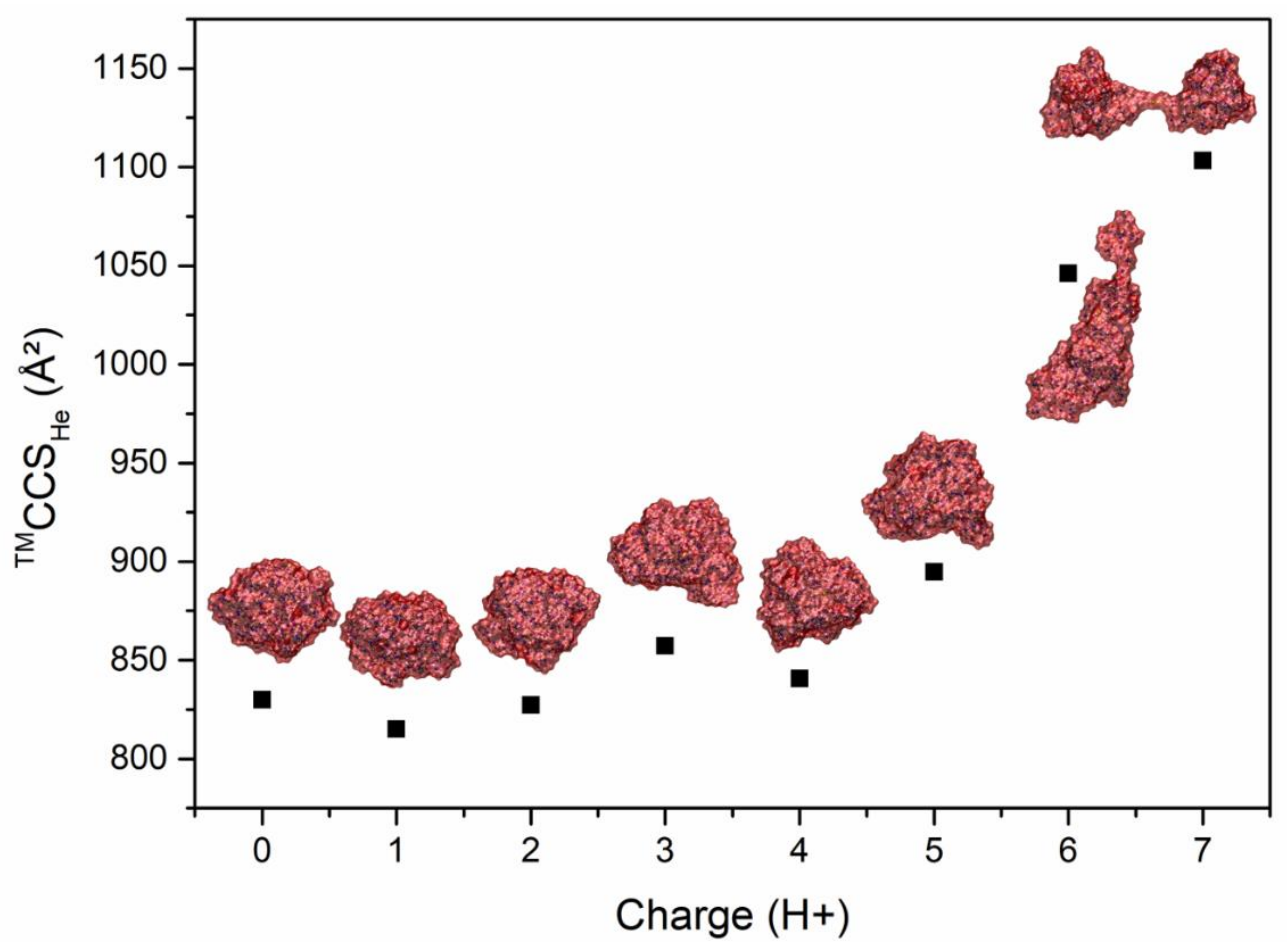

Figure S12: Evolution of the ${ }^{\mathrm{TM}} \mathrm{CCS}_{\mathrm{He}}$ for CYS PAMAM G3 from 0 to 7 charges. For each charge state, the structure is represented with the vdW surface in red. 
Table S3: Molecular dynamics simulation of the globular PAMAM ions and neutrals: theoretical CCS, SASA, $\mathrm{V}_{\text {SASA }}$ and corresponding densities.

\begin{tabular}{|c|c|c|c|c|c|c|c|}
\hline \multicolumn{8}{|c|}{ EDA PAMAM } \\
\hline $\mathrm{G}_{\mathrm{x}}$ & Charge & MW (Da) & ${ }^{\mathrm{TM}} \mathrm{CCS}_{\mathrm{He}}\left(\AA^{2}\right)$ & SASA $\left(\AA^{2}\right)$ & $\mathrm{V}_{\text {SASA }}\left(\AA^{3}\right)$ & $\rho_{S A S A}\left(\mathrm{Da} / \AA^{3}\right)^{\mathrm{a}}$ & $\rho_{C C S}\left(\mathrm{Da} / \AA^{3}\right)^{\mathrm{a}, \mathrm{b}}$ \\
\hline \multirow{3}{*}{ G0 } & 0 & 516 & 146 & 673 & 1329 & $0.39(0.65)$ & $0.39(0.65)$ \\
\hline & +1 & 517 & 145 & 663 & 1315 & $0.39(0.65)$ & $0.39(0.65)$ \\
\hline & +2 & 518 & 155 & 676 & 1339 & $0.39(0.65)$ & $0.36(0.60)$ \\
\hline \multirow{3}{*}{ G1 } & 0 & 1429 & 284 & 1219 & 3080 & $0.46(0.76)$ & $0.40(0.66)$ \\
\hline & +1 & 1430 & 279 & 1217 & 3080 & $0.46(0.76)$ & $0.41(0.68)$ \\
\hline & +2 & 1431 & 292 & 1257 & 3119 & $0.46(0.76)$ & $0.38(0.63)$ \\
\hline \multirow{4}{*}{$\mathrm{G} 2$} & 0 & 3255 & 505 & 2153 & 6524 & $0.50(0.83)$ & $0.38(0.63)$ \\
\hline & +1 & 3256 & 489 & 2050 & 6366 & $0.51(0.85)$ & $0.40(0.66)$ \\
\hline & +2 & 3257 & 505 & 2122 & 6422 & $0.51(0.85)$ & $0.38(0.63)$ \\
\hline & +3 & 3258 & 519 & 2209 & 6607 & $0.49(0.81)$ & $0.37(0.61)$ \\
\hline \multirow{5}{*}{ G3 } & 0 & 6908 & 821 & 3354 & 12678 & $0.54(0.91)$ & $0.39(0.65)$ \\
\hline & +1 & 6909 & 824 & 3406 & 12656 & $0.55(0.90)$ & $0.39(0.65)$ \\
\hline & +2 & 6910 & 820 & 3322 & 12499 & $0.55(0.90)$ & $0.39(0.65)$ \\
\hline & +3 & 6911 & 827 & 3427 & 12876 & $0.54(0.91)$ & $0.39(0.65)$ \\
\hline & +4 & 6912 & 843 & 3427 & 12796 & $0.54(0.91)$ & $0.38(0.63)$ \\
\hline \multicolumn{8}{|c|}{ CYS PAMAM } \\
\hline $\mathrm{G}_{\mathrm{x}}$ & Charge & MW (Da) & ${ }^{\mathrm{TM}} \mathrm{CCS}_{\mathrm{He}}\left(\AA^{2}\right)$ & SASA $\left(\AA^{2}\right)$ & $\mathrm{V}_{\text {SASA }}\left(\AA^{3}\right)$ & psASA $\left(\mathrm{Da} / \AA^{3}\right)^{\mathrm{a}}$ & $\rho c C S\left(D a / \AA^{3}\right)^{a, b}$ \\
\hline \multirow{3}{*}{ G0 } & 0 & 608 & 162 & 770 & 1539 & $0.40(0.66)$ & $0.39(0.65)$ \\
\hline & +1 & 609 & 162 & 738 & 1496 & $0.41(0.68)$ & $0.39(0.65)$ \\
\hline & +2 & 610 & 168 & 758 & 1519 & $0.40(0.66)$ & $0.37(0.61)$ \\
\hline \multirow{3}{*}{ G1 } & 0 & 1521 & 297 & 1295 & 3299 & $0.46(0.76)$ & $0.40(0.66)$ \\
\hline & +1 & 1522 & 289 & 1251 & 3267 & $0.47(0.78)$ & $0.41(0.68)$ \\
\hline & +2 & 1523 & 305 & 1326 & 3314 & $0.46(0.76)$ & $0.38(0.63)$ \\
\hline \multirow{3}{*}{ G2 } & 0 & 3348 & 507 & 2107 & 6601 & $0.51(0.85)$ & $0.39(0.65)$ \\
\hline & +1 & 3349 & 495 & 2059 & 6498 & $0.52(0.86)$ & $0.40(0.66)$ \\
\hline & +2 & 3350 & 521 & 2191 & 6723 & $0.50(0.83)$ & $0.37(0.61)$ \\
\hline \multirow{5}{*}{ G3 } & 0 & 7001 & 830 & 3404 & 12847 & $0.54(0.91)$ & $0.39(0.65)$ \\
\hline & +1 & 7002 & 815 & 3319 & 12719 & $0.55(0.90)$ & $0.40(0.66)$ \\
\hline & +2 & 7003 & 827 & 3377 & 12819 & $0.55(0.90)$ & $0.39(0.65)$ \\
\hline & +3 & 7004 & 857 & 3579 & 13026 & $0.54(0.91)$ & $0.37(0.61)$ \\
\hline & +4 & 7005 & 841 & 3508 & 13053 & $0.54(0.91)$ & $0.38(0.63)$ \\
\hline
\end{tabular}



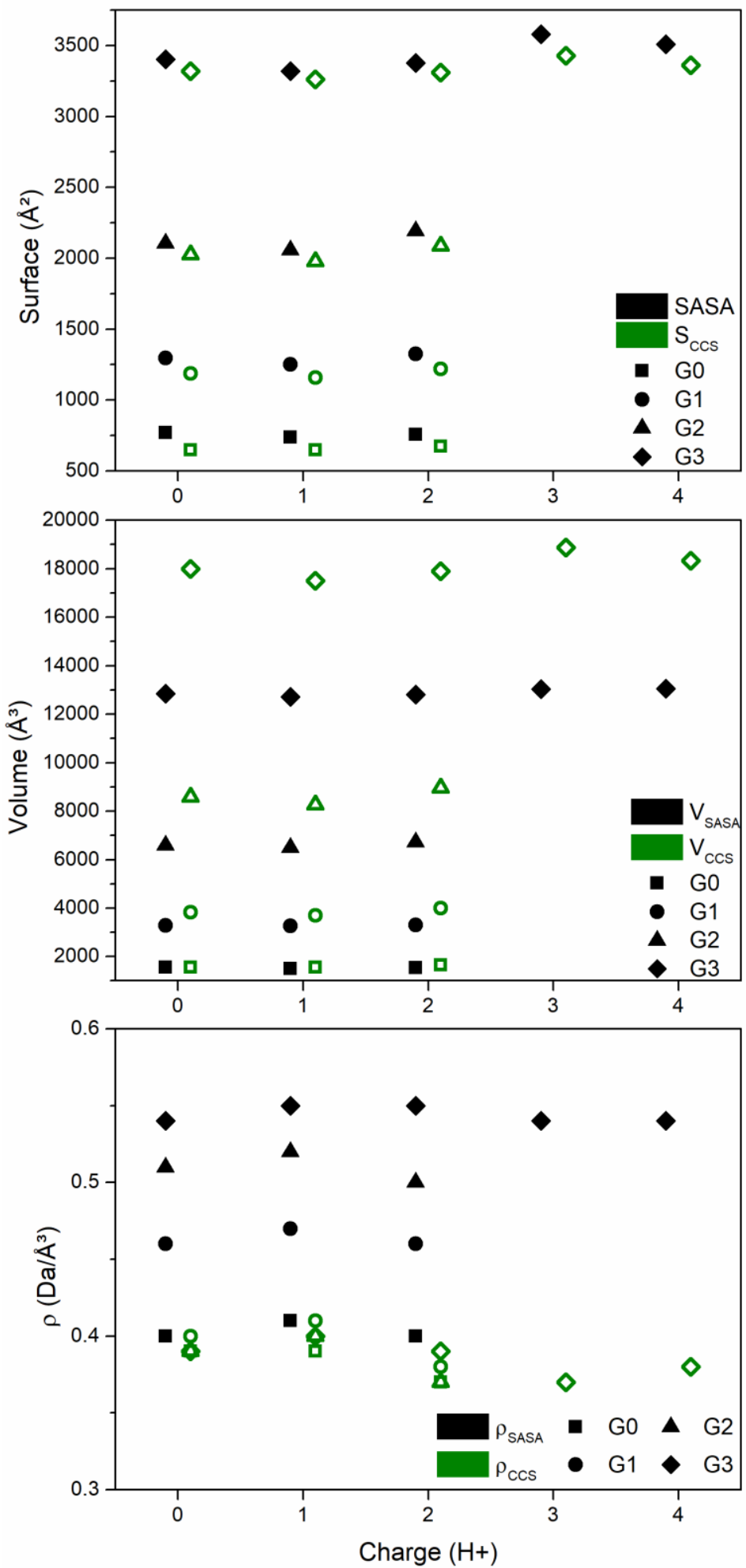

Figure S13: Comparison between surfaces (top), volumes (middle) and densities (bottom) from the last frame of the MD (black, solid) and calculated based on the average ${ }^{\mathrm{TM}} \mathrm{CCS} \mathrm{He}_{\mathrm{He}}$ on 200 frames (green, hollow) of CYS PAMAM ions and neutrals for G0 to G3. 


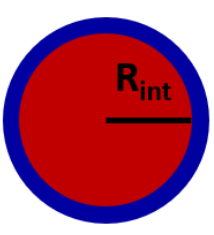

$$
\mathrm{R}_{\text {int }}=5
$$

$V_{\text {tot }}=905$

$\mathrm{V}_{\text {shell }}=381$

$42 \%$

$$
\mathrm{V}_{\text {tot }}=\frac{4 \pi}{3}\left(R_{\text {int }}+R_{\text {probe }}\right)^{3}
$$

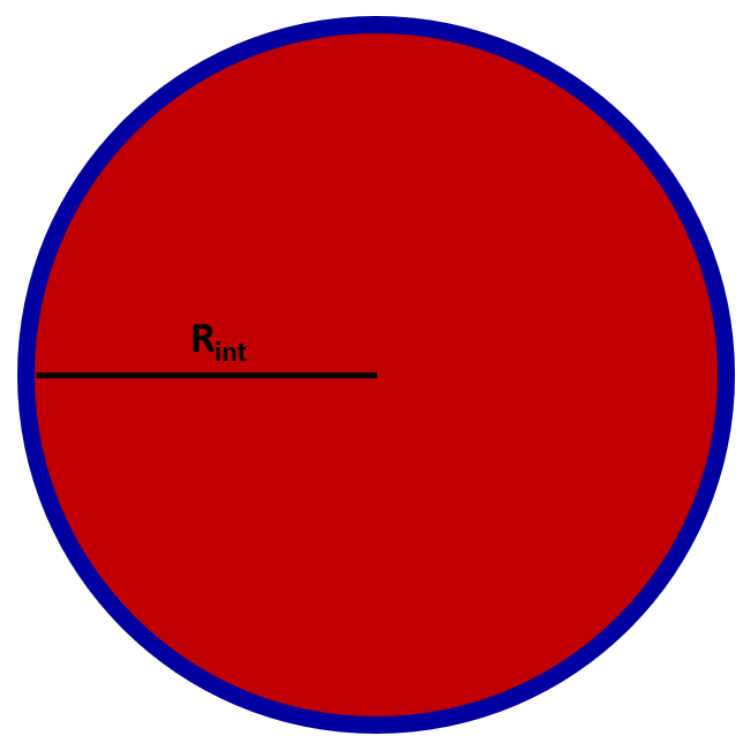

$$
\mathrm{R}_{\text {probe }}=1
$$$$
\mathrm{R}_{\text {int }}=20
$$$$
\mathrm{V}_{\text {tot }}=38792
$$$$
\mathrm{V}_{\text {shell }}=5282
$$

$14 \%$

Figure S14: Representation of the extra volume due to the probe decreasing with the radius of the molecule. For a probe radius of 1 in arbitrary units, the shell represents $42 \%$ of the total volume for an internal radius of 5 while it represents only $14 \%$ for an internal radius of 20. For the development of the equation for the $\mathrm{V}_{\text {shell }}$ calculation, see the end of the SI.

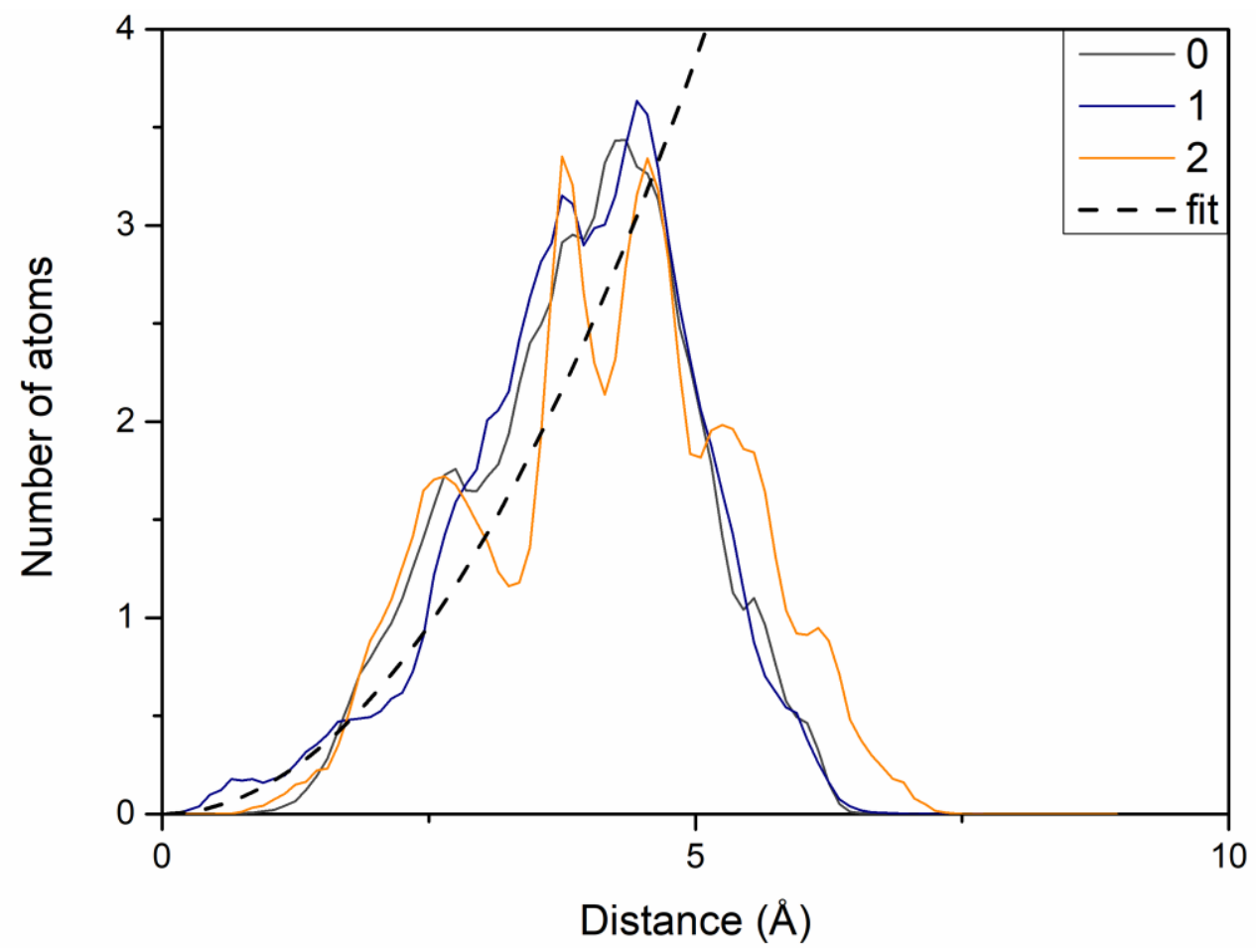

Figure S15: Number of atoms found in concentric shells $0.1 \AA$ thick, as a function of the distance from the geometrical center. Results of EDA G0, for charge states 0 to +2 . The average parabolic fit corresponding to a dense core model is displayed in dashed lines. The fit for all the generations differs from the curves for G0. 


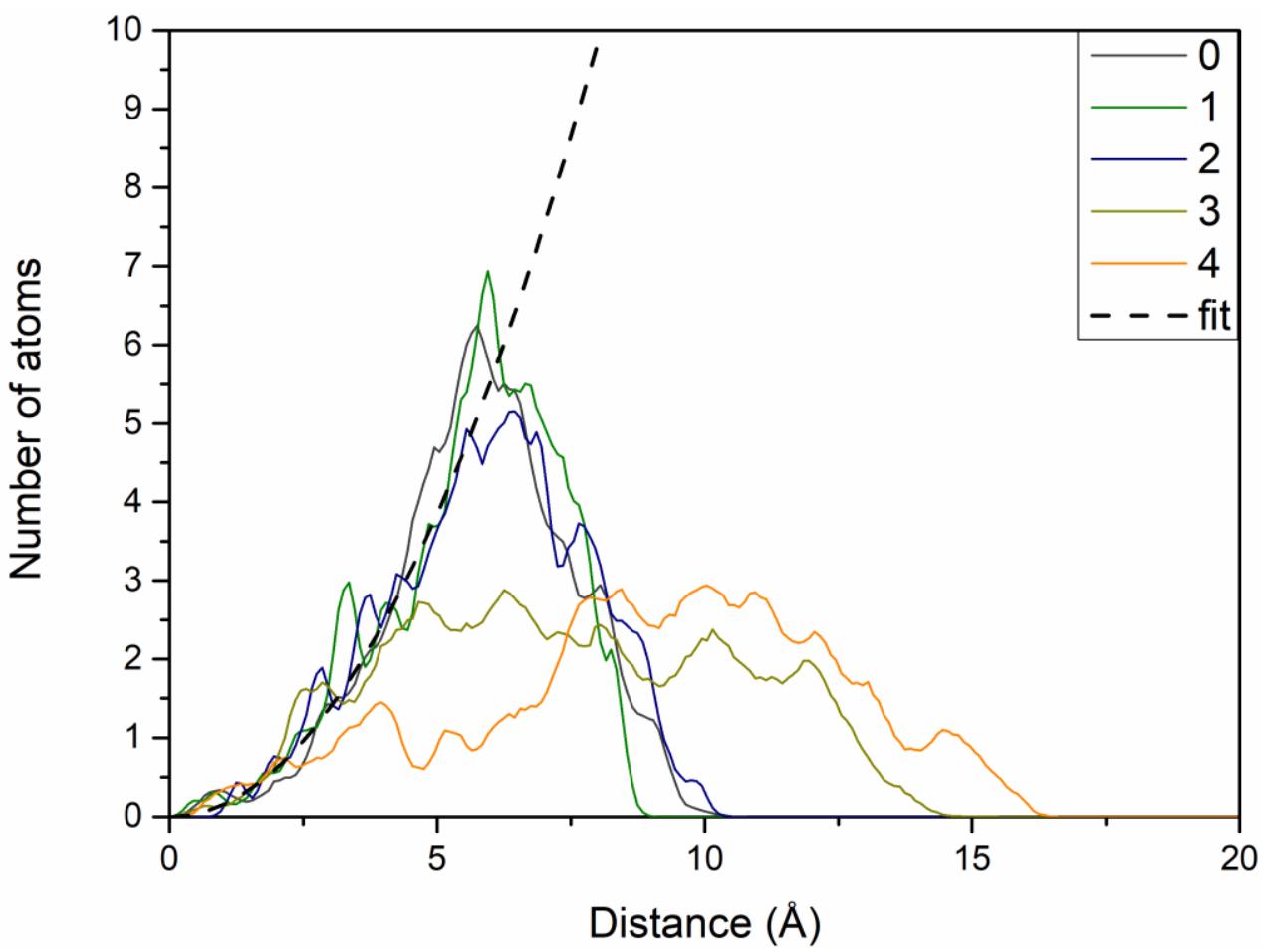

Figure S16: Number of atoms found in concentric shells 0.1 Å thick, as a function of the distance from the geometrical center. Results of EDA G1, for charge states 0 to +4 . A parabolic fit corresponding to a dense core model is displayed in dashed lines.

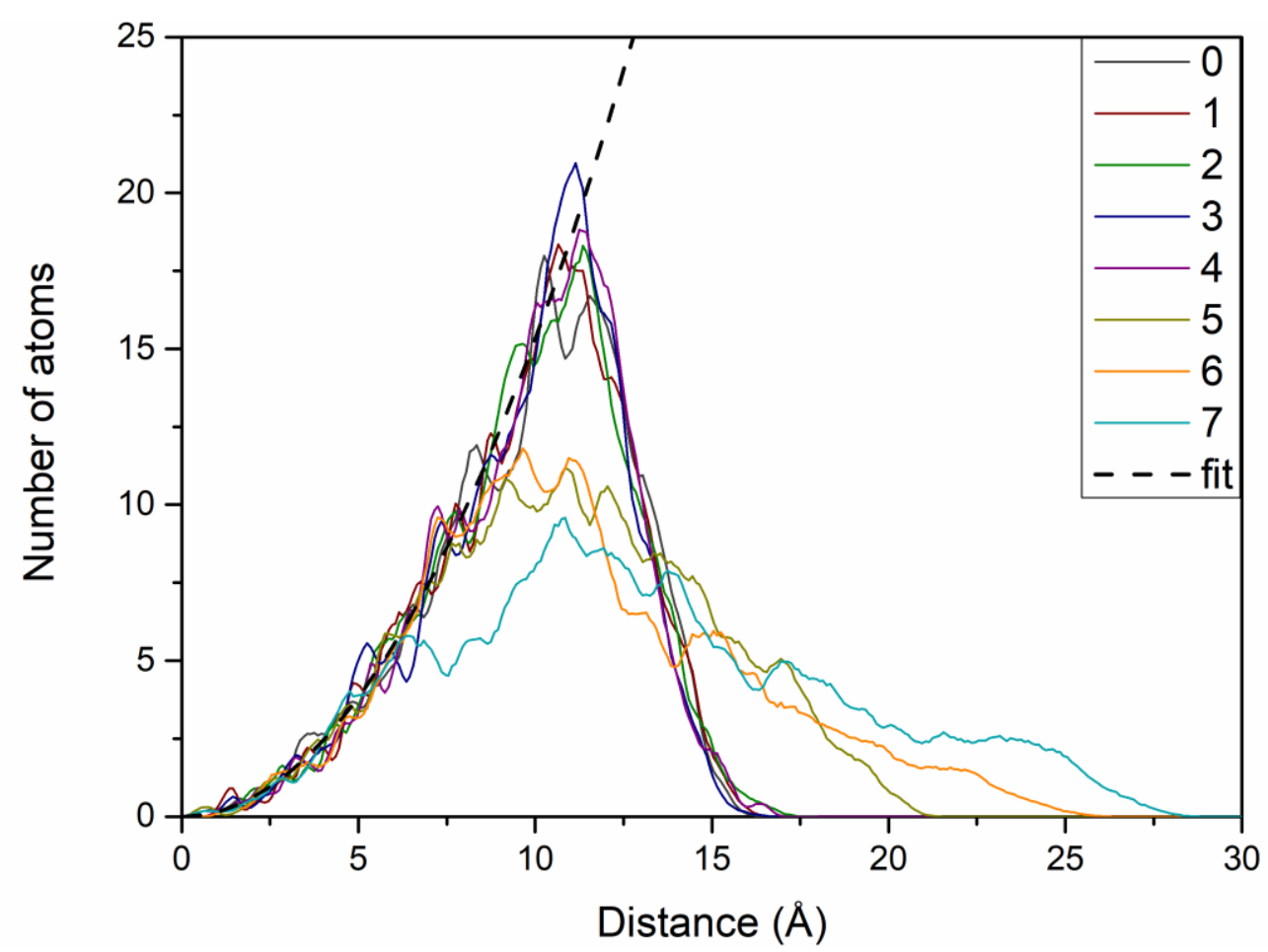

Figure S17: Number of atoms found in concentric shells $0.1 \AA$ thick, as a function of the distance from the geometrical center. Results of EDA G3, for charge states 0 to +7 . A parabolic fit corresponding to a dense core model is displayed in dashed lines. 


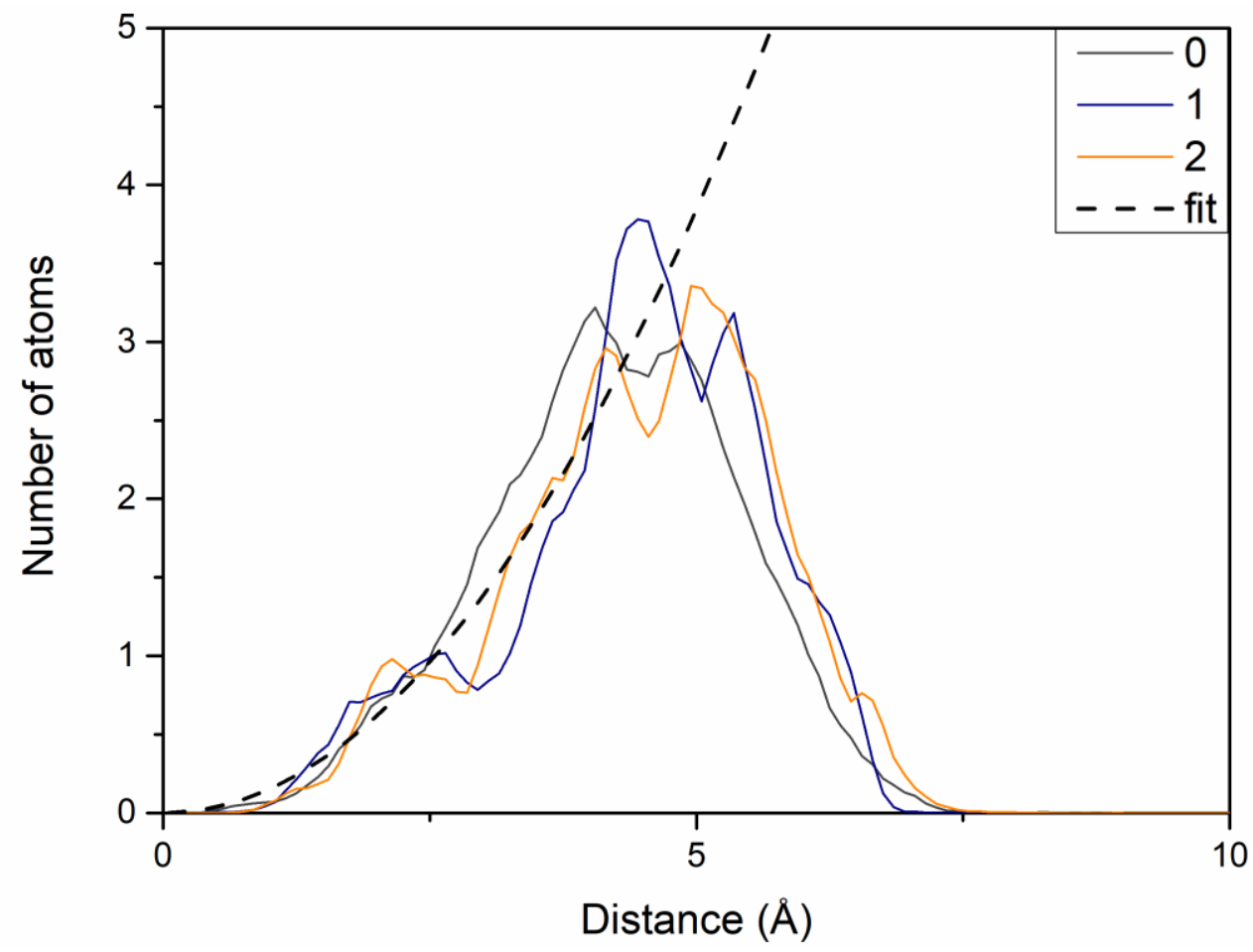

Figure S18: Number of atoms found in concentric shells $0.1 \AA$ thick, as a function of the distance from the geometrical center. Results of CYS G0, for charge states 0 to +2 . The average parabolic fit corresponding to a dense core model is displayed in dashed lines. The fit for all the generations differs from the curves for G0.

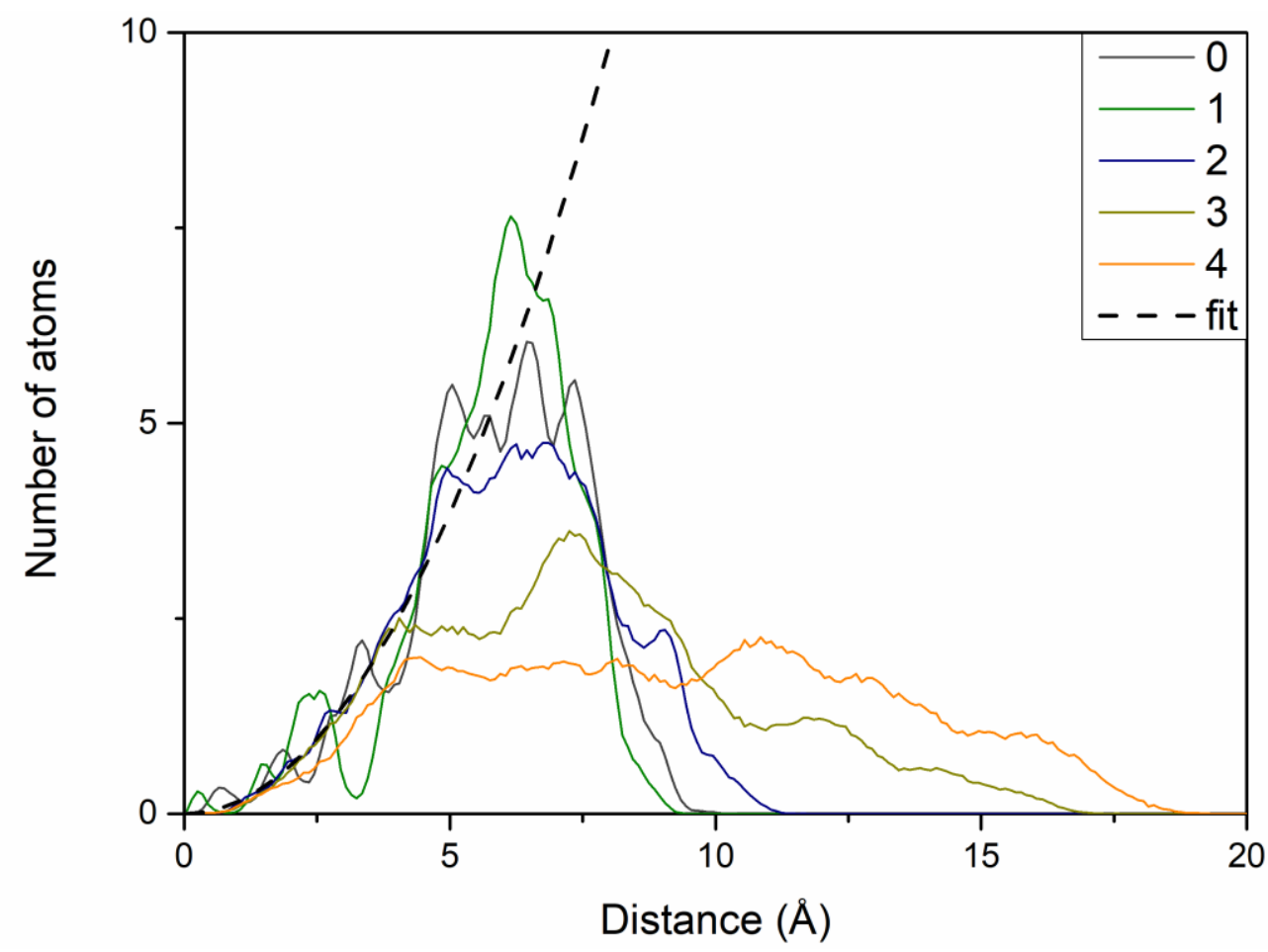

Figure S19: Number of atoms found in concentric shells $0.1 \AA$ thick, as a function of the distance from the geometrical center. Results of CYS G1, for charge states 0 to +4 . A parabolic fit corresponding to a dense core model is displayed in dashed lines. 


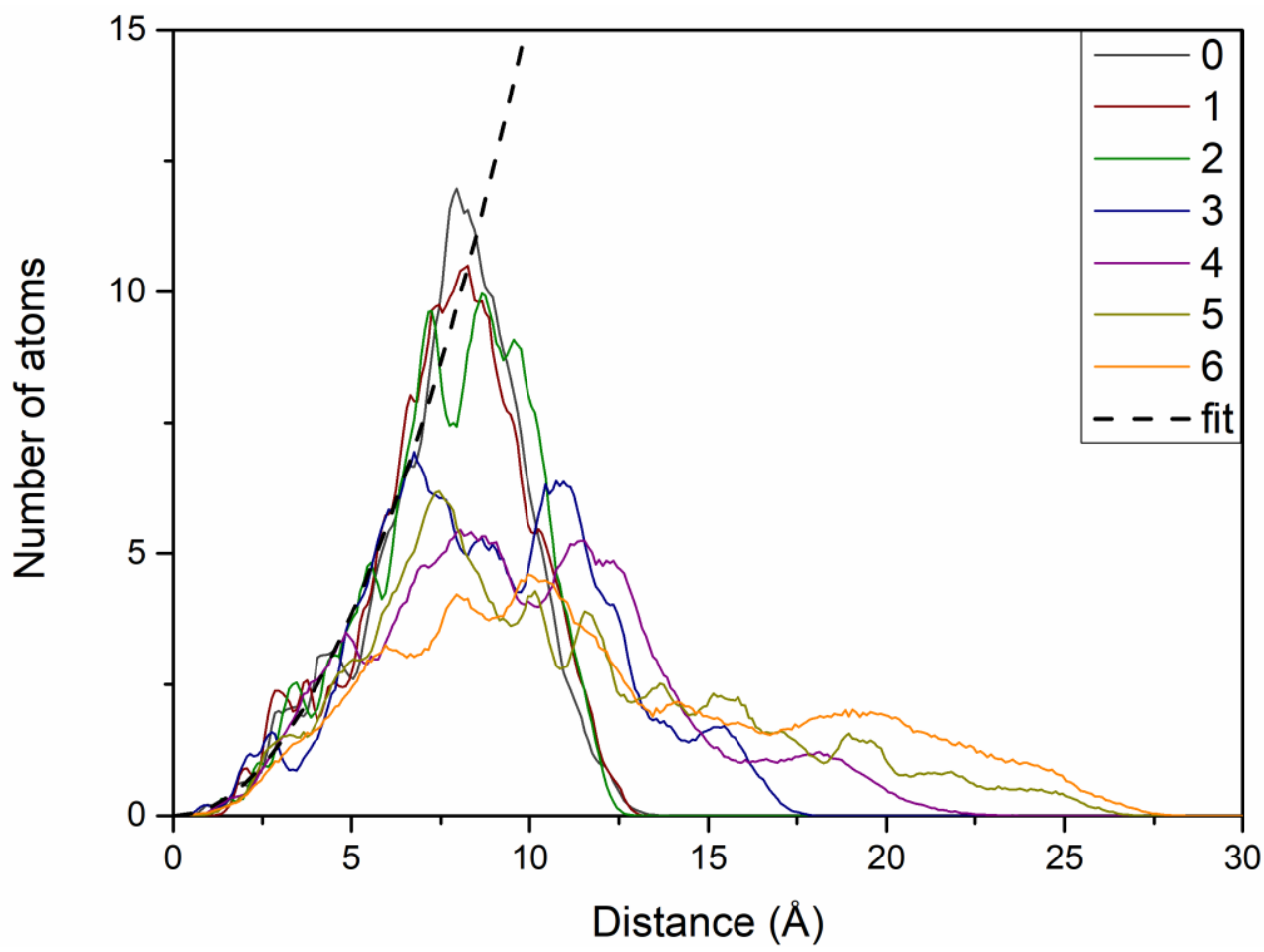

Figure S20: Number of atoms found in concentric shells $0.1 \AA$ thick, as a function of the distance from the geometrical center. Results of CYS G2, for charge states 0 to +6 . A parabolic fit corresponding to a dense core model is displayed in dashed lines.

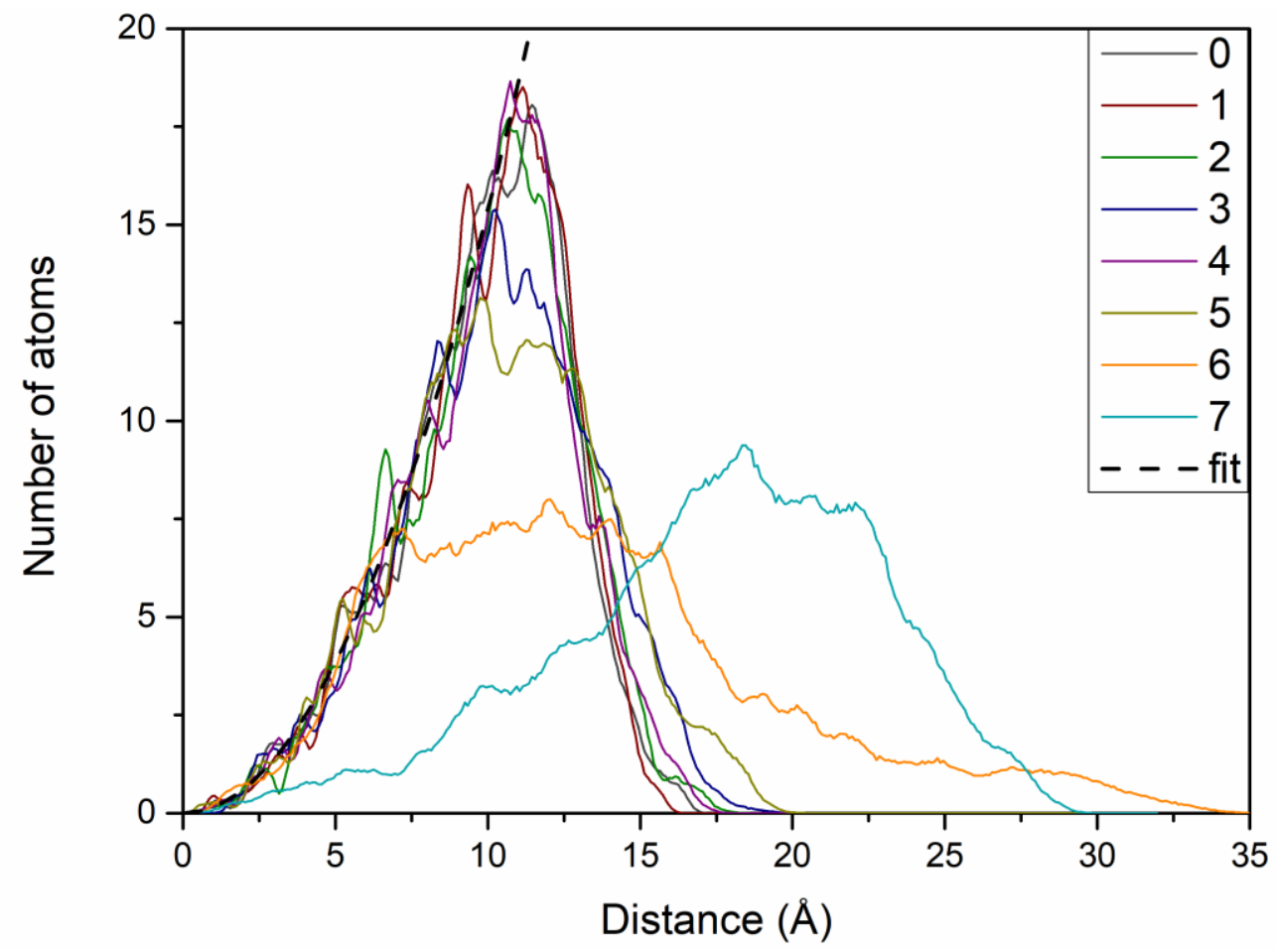

Figure S21: Number of atoms found in concentric shells $0.1 \AA$ thick, as a function of the distance from the geometrical center. Results of CYS G3, for charge states 0 to +7 . A parabolic fit corresponding to a dense core model is displayed in dashed lines. 


\section{PPI}

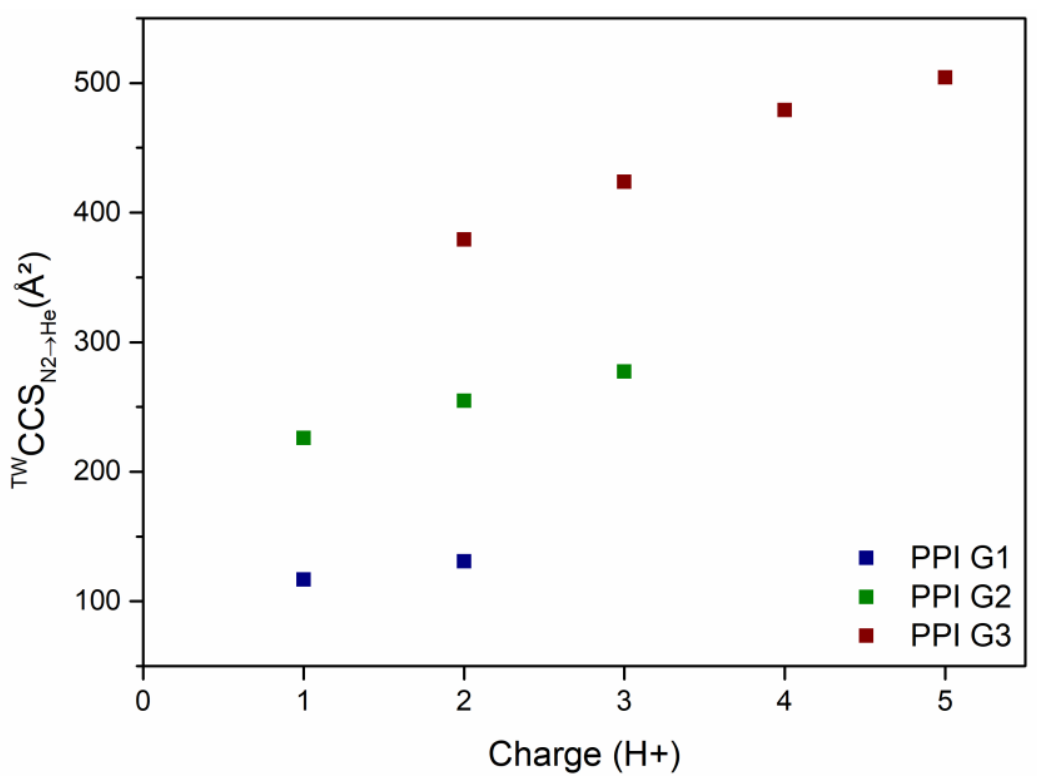

Figure S22: Evolution of the experimental ${ }^{\mathrm{TW}} \mathrm{CCS}_{\mathrm{N} 2 \rightarrow \mathrm{He}}$ as a function of the charge state for PPI from G1 to G3.

Table S4: ${ }^{\mathrm{TW}} \mathrm{CCS}_{\mathrm{N} 2 \rightarrow \mathrm{He}}$ and ${ }^{\mathrm{DT}} \mathrm{CCS}_{\mathrm{He}}$ of PPI ions

\begin{tabular}{|l|l|l|l|l|l|l|l|}
\hline \multicolumn{7}{|l|}{ PPI } \\
\hline \multirow{2}{*}{$\mathrm{G}_{\mathrm{x}}$} & charge & $m / z$ & ${ }^{T W} C C S_{N 2 \rightarrow H e}\left(\AA^{2}\right)$ & ${ }^{D T} \mathrm{CCS}_{\mathrm{He}}\left(\AA^{2}\right)$ & $\Delta \mathrm{CCS}(\%)^{\mathrm{a}}$ & $\begin{array}{l}{ }^{T W} C C S_{N 2} \rightarrow H e \\
\text { single calibration }\end{array}$ & $\left.\Delta \mathrm{C} \AA^{2}\right)$ \\
\hline \multirow{2}{*}{$\mathrm{G} 1$} & +1 & 317 & $117 \pm 2$ & 123 & +4.8 & 129 & +10.3 \\
\cline { 2 - 8 } & +2 & 159 & $131 \pm 4$ & 139 & +6.1 & 150 & +14.5 \\
\hline \multirow{2}{*}{$\mathrm{G} 2$} & +2 & 387 & $255 \pm 2$ & 256 & +0.6 & 247 & -3.0 \\
\cline { 2 - 8 } & +3 & 259 & $277 \pm 4$ & 272 & -2.0 & 266 & -4.2 \\
\hline \multirow{2}{*}{$\mathrm{G} 3$} & +3 & 563 & $424 \pm 3$ & 444 & +4.7 & 412 & -2.7 \\
\cline { 2 - 7 } & +4 & 423 & $479 \pm 4$ & 504 & +5.2 & 458 & -4.4 \\
\hline
\end{tabular}

Table S5: Experimental and theoretical CCS of PPI ions.

\begin{tabular}{|c|c|c|c|c|c|}
\hline \multicolumn{6}{|l|}{ PPI } \\
\hline $\mathrm{G}_{\mathrm{x}}$ & charge & $m / z$ & ${ }^{T W} C C S_{N 2 \rightarrow H e}\left(\AA^{2}\right)$ & ${ }^{\mathrm{TM}} \mathrm{CCS}_{\mathrm{He}}\left(\AA^{2}\right)$ & $\Delta \mathrm{CCS}(\%)$ \\
\hline \multirow{2}{*}{ G1 } & +1 & 317 & $117 \pm 2$ & $115 \pm 2$ & 1.8 \\
\hline & +2 & 159 & $131 \pm 4$ & $138 \pm 1$ & 5.7 \\
\hline \multirow{3}{*}{ G2 } & +1 & 774 & $226 \pm 1$ & $216 \pm 6$ & 4.4 \\
\hline & +2 & 387 & $255 \pm 2$ & $249 \pm 4$ & 2.4 \\
\hline & +3 & 259 & $277 \pm 4$ & $268 \pm 5$ & 3.4 \\
\hline \multirow{4}{*}{ G3 } & +2 & 844 & $379 \pm 1$ & $378 \pm 8$ & 0.4 \\
\hline & +3 & 563 & $424 \pm 3$ & $424 \pm 7$ & 0.0 \\
\hline & +4 & 423 & $479 \pm 4$ & $499 \pm 8$ & 4.1 \\
\hline & +5 & 338 & $504 \pm 4$ & $519 \pm 7$ & 2.9 \\
\hline
\end{tabular}




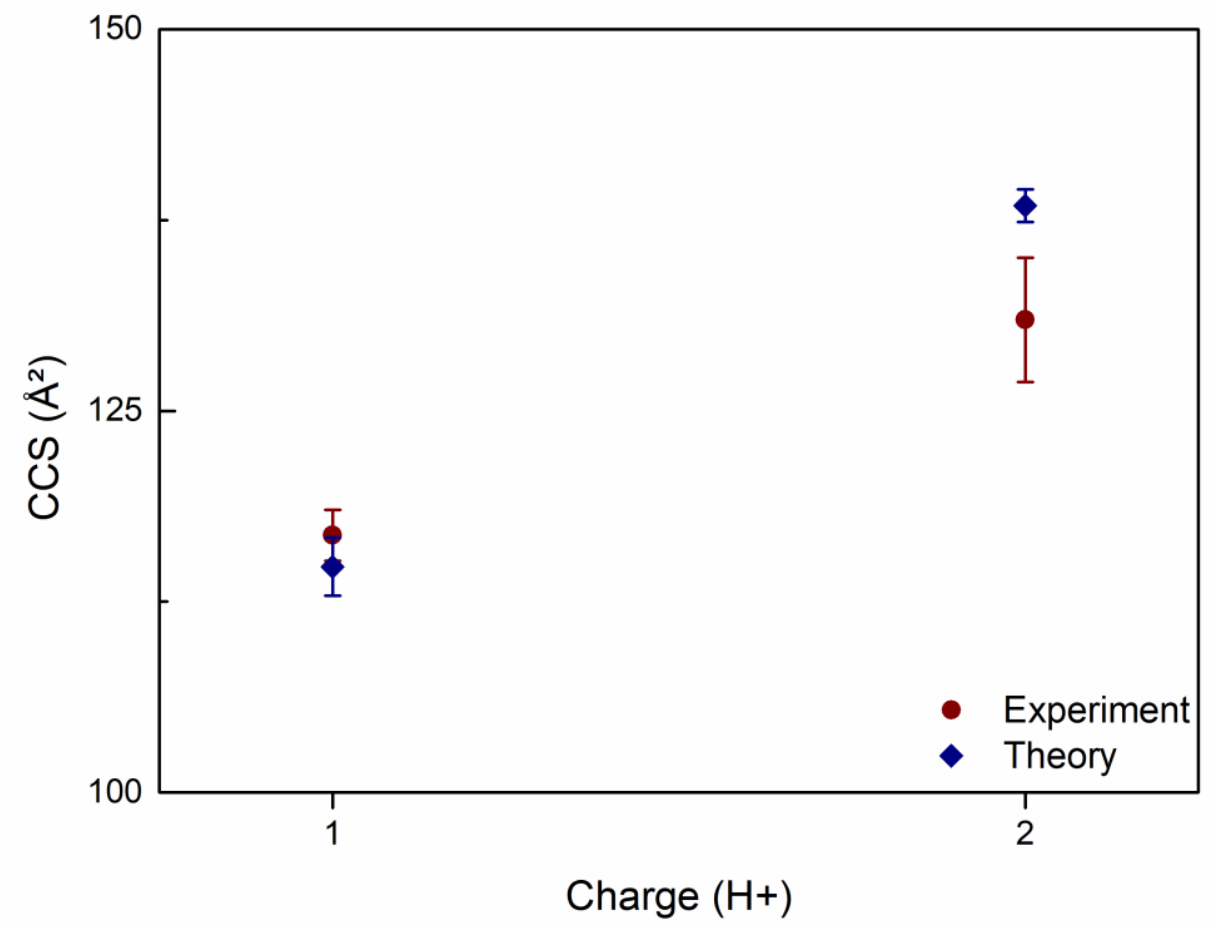

Figure S23: Comparison between experimental (red circle) and theoretical (blue diamond) CCS for PPI G1. Error bars represent the standard deviation on 5 experimental measurements, and on 200 theoretical structures, respectively.

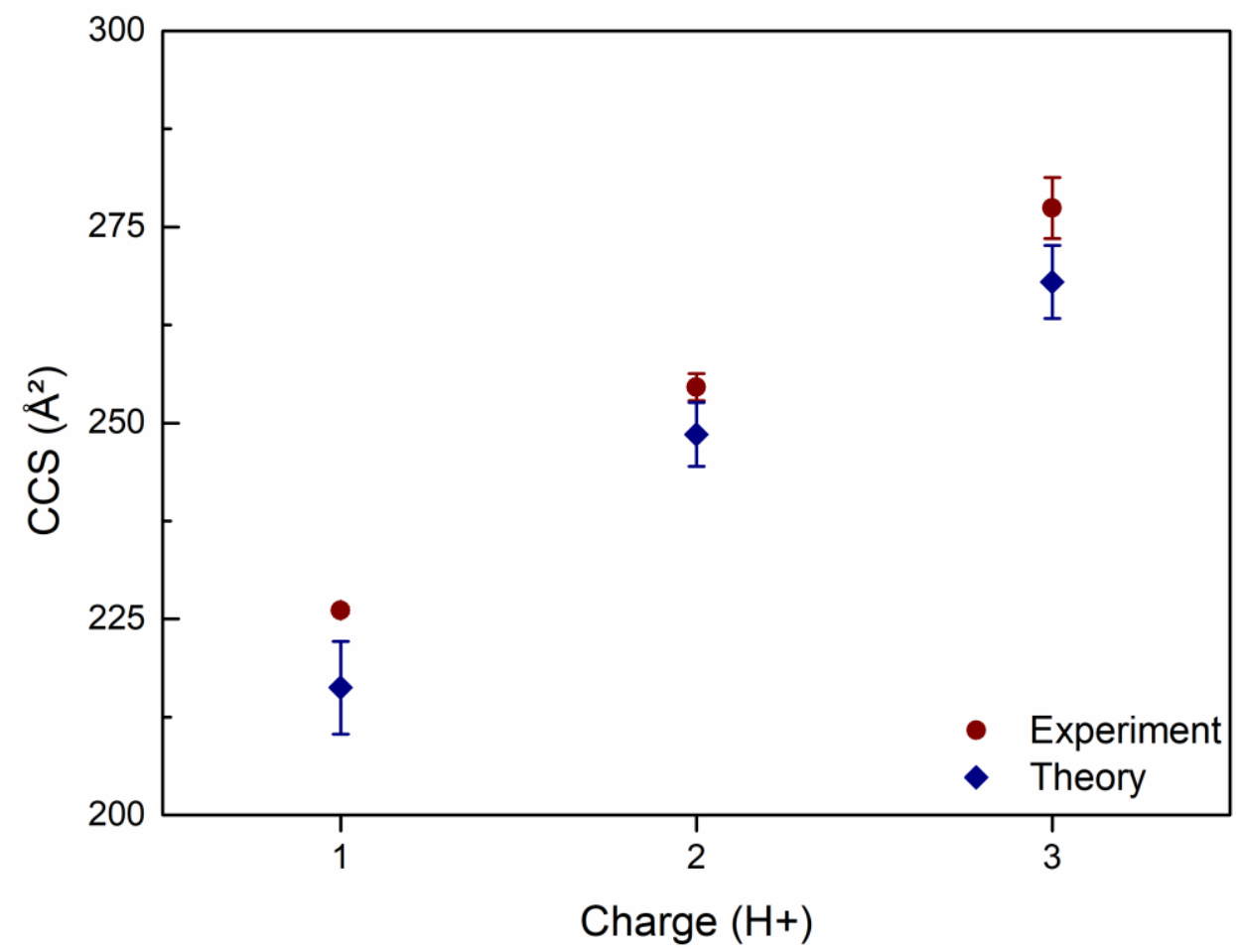

Figure S24: Comparison between experimental (red circle) and theoretical (blue diamond) CCS for PPI G2. Error bars represent the standard deviation on 3 experimental measurements, and on 200 theoretical structures, respectively. 


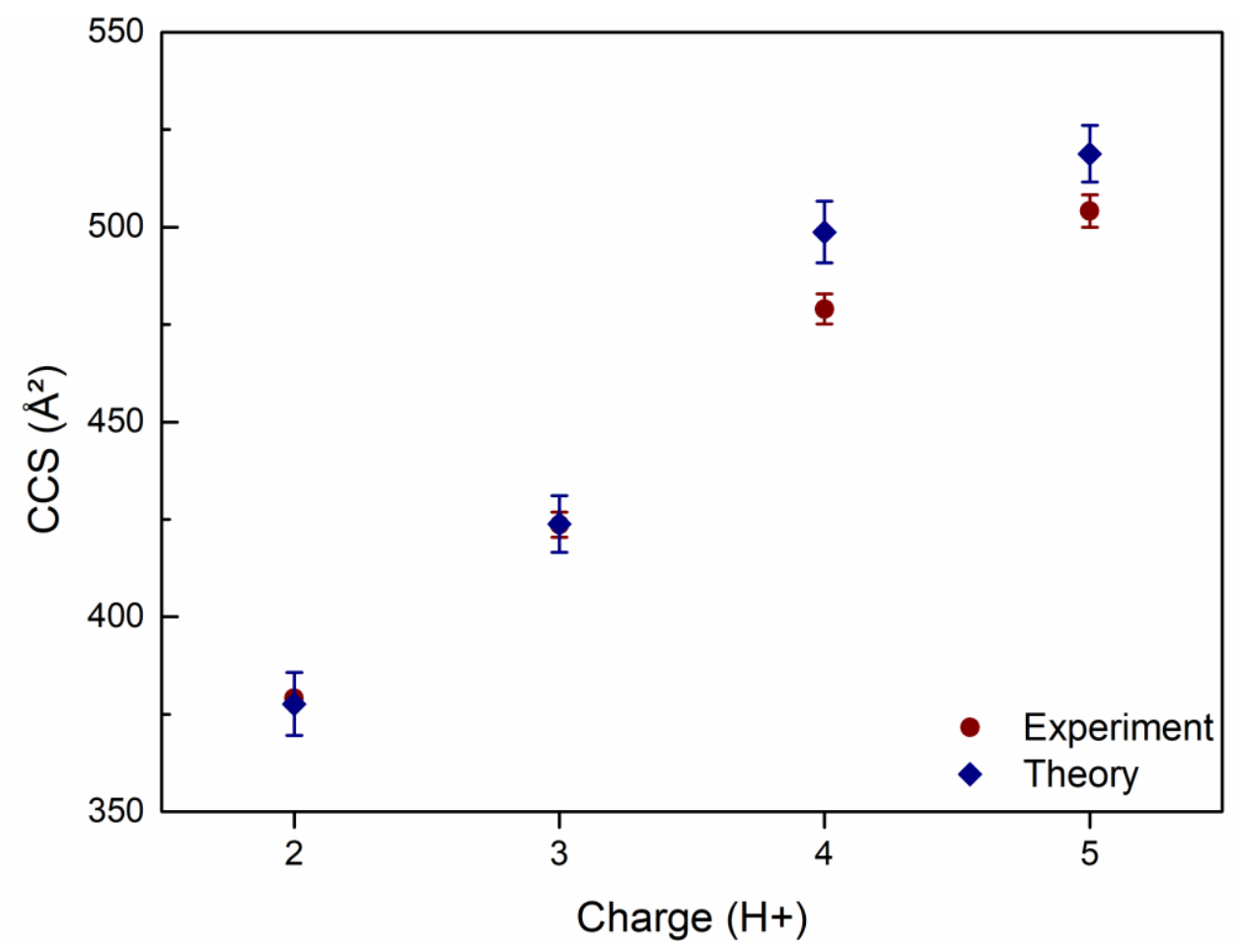

Figure S25: Comparison between experimental (red circle) and theoretical (blue diamond) CCS for PPI G3. Error bars represent the standard deviation on 3 experimental measurements, and on 200 theoretical structures, respectively.

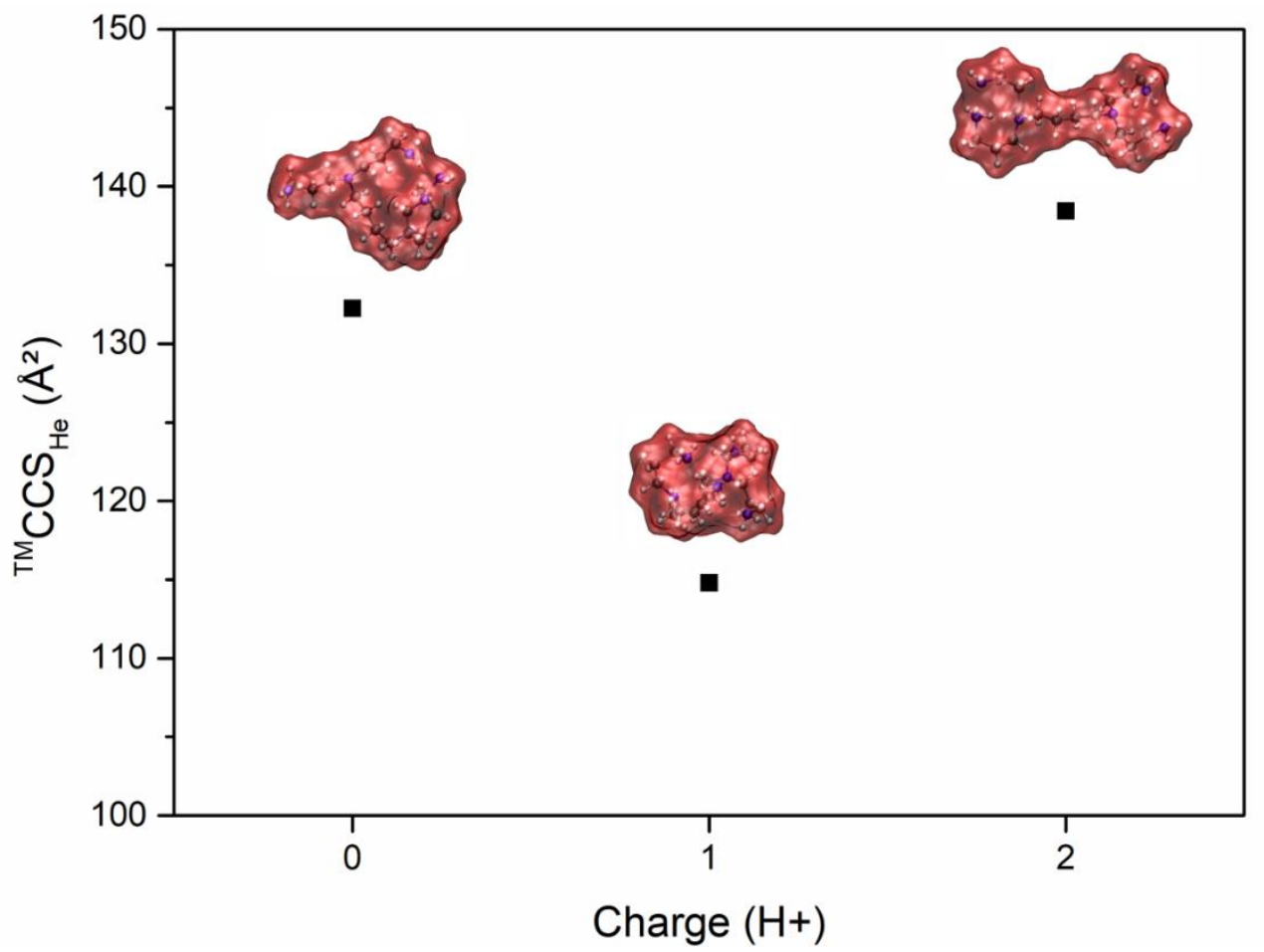

Figure S26: Evolution of the theoretical ${ }^{\mathrm{TM}} \mathrm{CCS}_{\mathrm{He}}$ for PPI G1 from 0 to 2 charges. For each charge state, the structure is represented with the Connolly surface in red. 


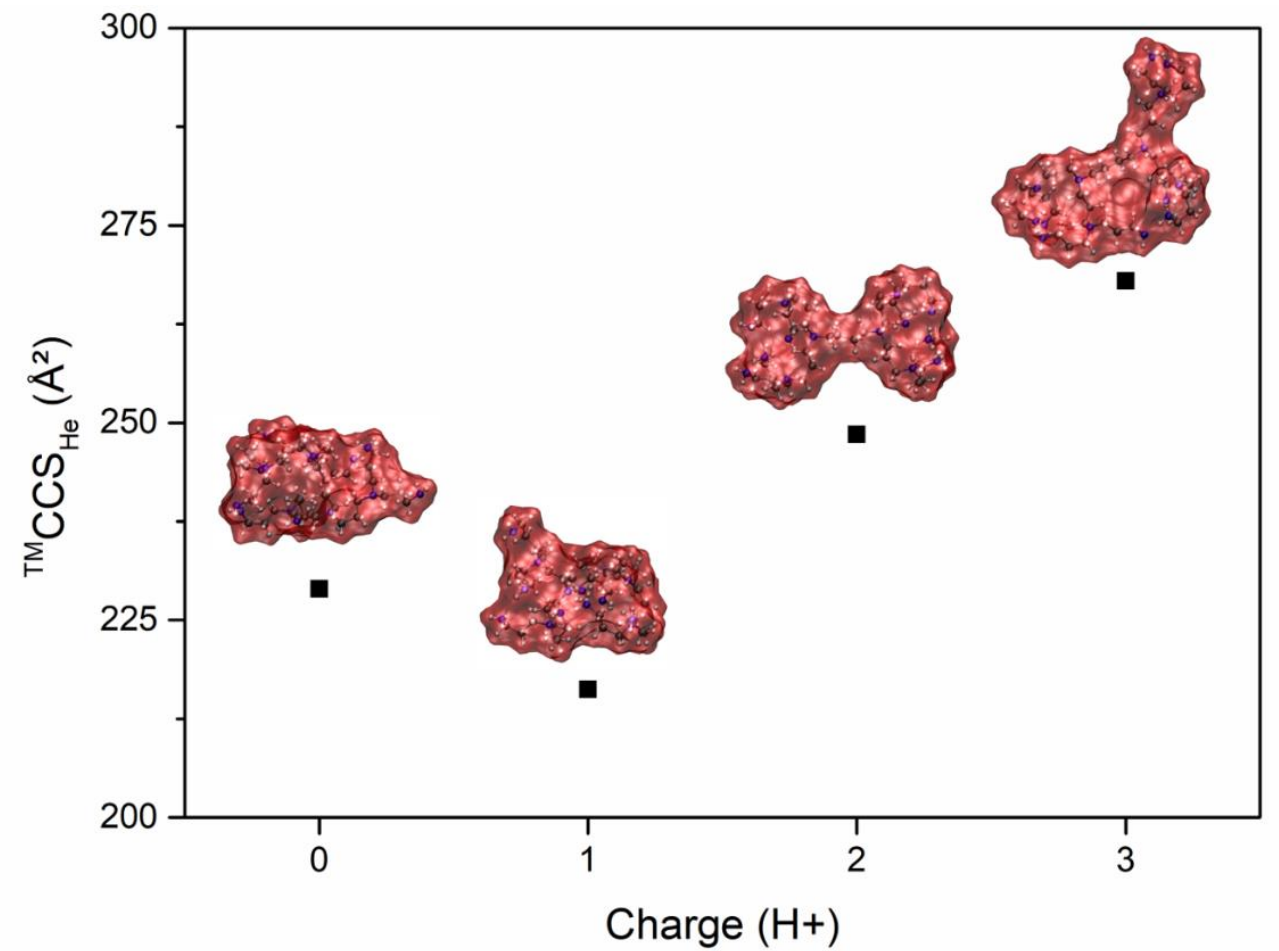

Figure S27: Evolution of the theoretical ${ }^{\mathrm{TM}} \mathrm{CCS}$ He for PPI G2 from 0 to 3 charges. For each charge state, the structure is represented with the Connolly surface in red.

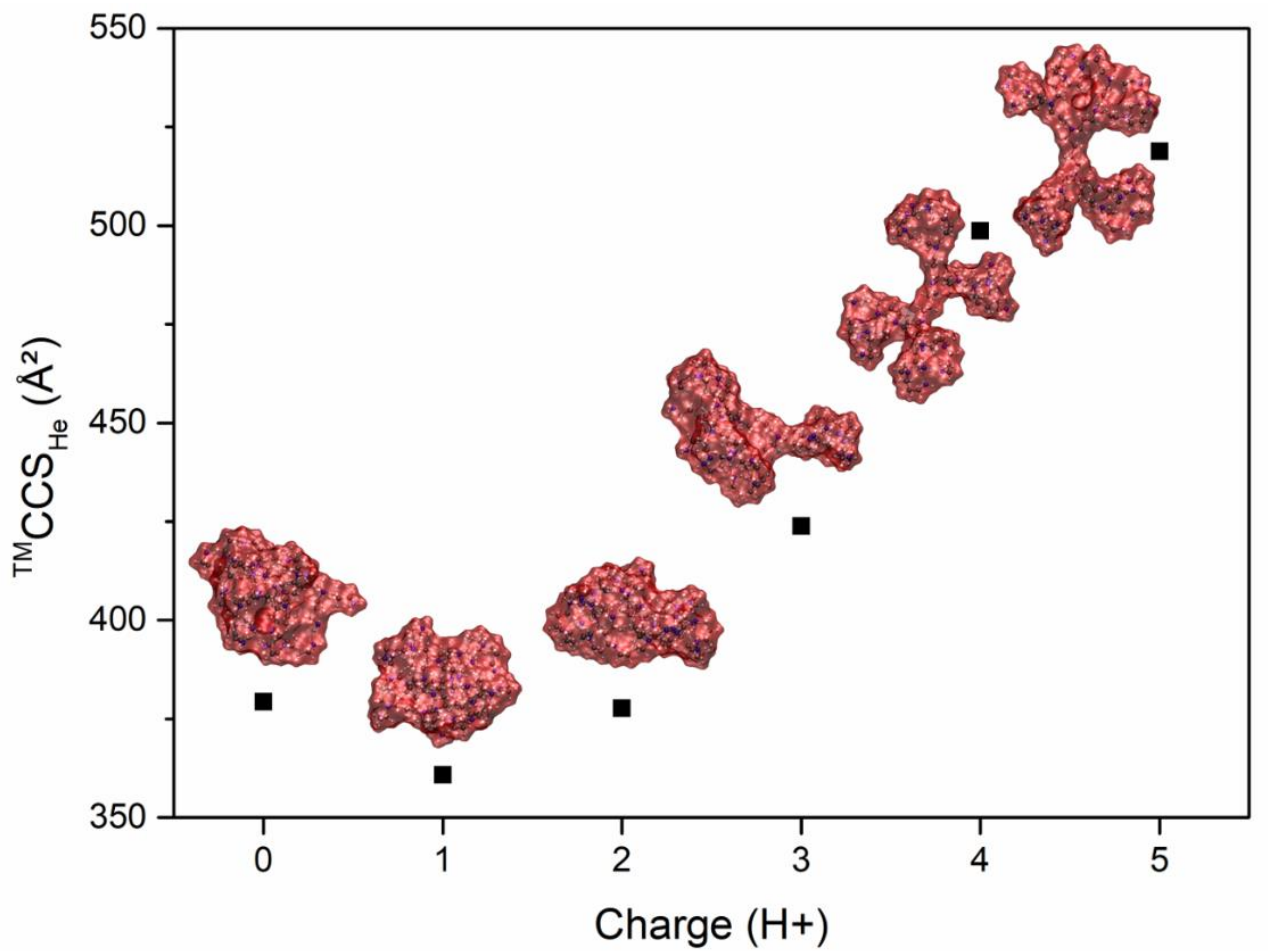

Figure S28: Evolution of the theoretical ${ }^{\mathrm{TM}} \mathrm{CCS}_{\mathrm{He}}$ for PPI G3 from 0 to 5 charges. For each charge state, the structure is represented with the Connolly surface in red. 


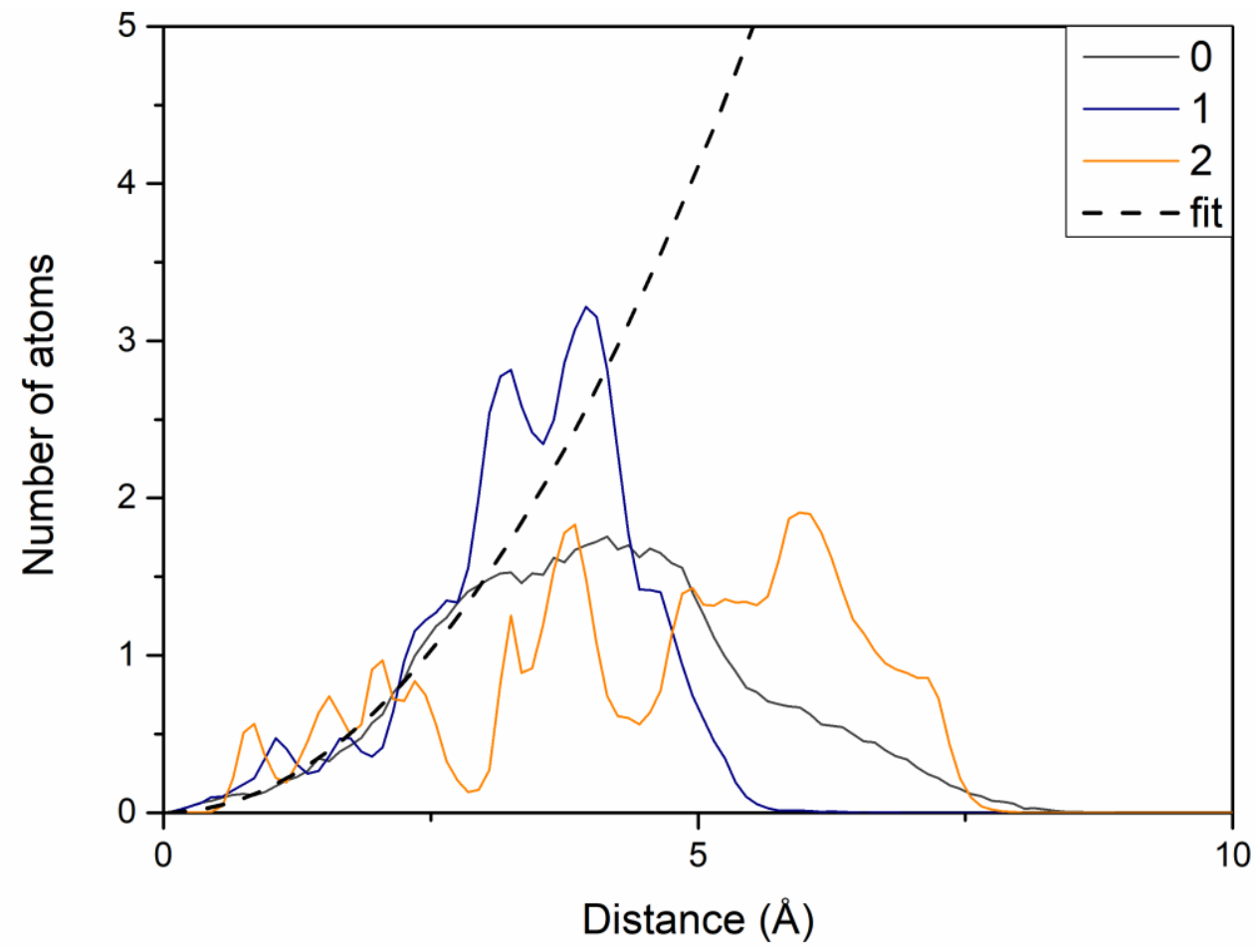

Figure S29: Number of atoms found in concentric shells $0.1 \AA$ thick, as a function of the distance from the geometrical center. Results of PPI G1, for charge states 0 to +2 . The average parabolic fit corresponding to a dense core model is displayed in dashed lines. The fit for all the generations differs from the curves for G1.

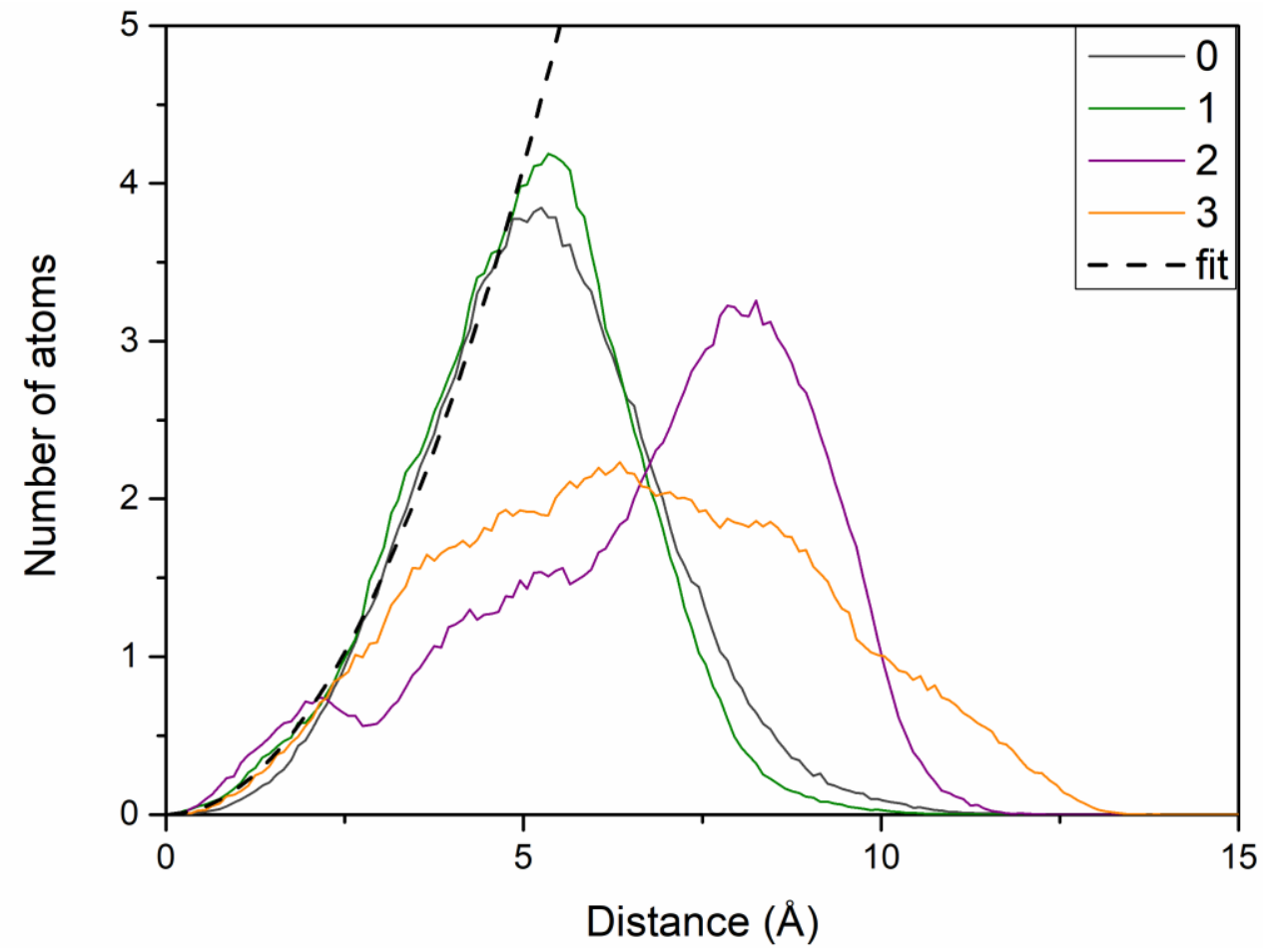

Figure S30: Number of atoms found in concentric shells $0.1 \AA$ thick, as a function of the distance from the geometrical center. Results of PPI G2, for charge states 0 to +3 . A parabolic fit corresponding to a dense core model is displayed in dashed lines. 


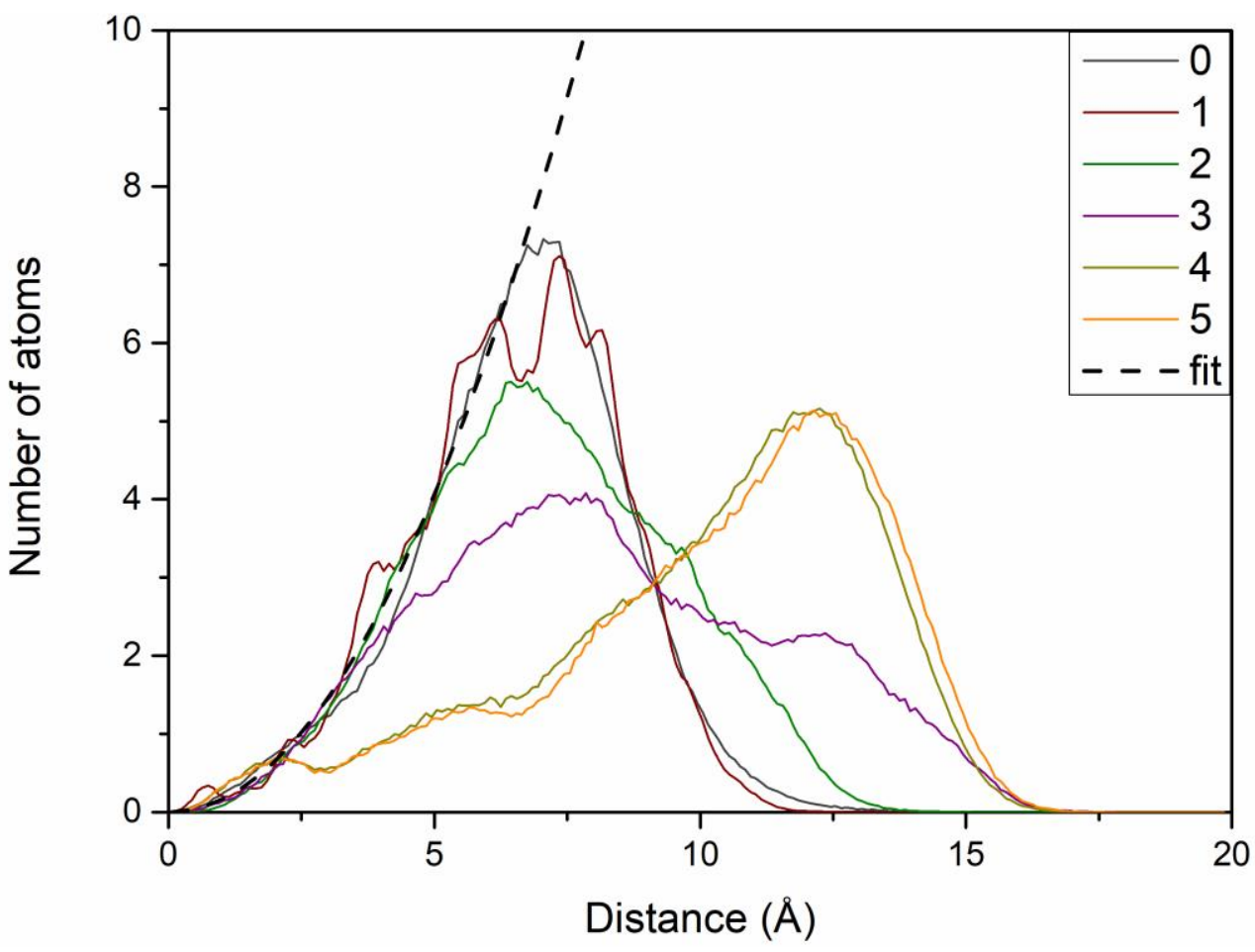

Figure S31: Number of atoms found in concentric shells $0.1 \AA$ thick, as a function of the distance from the geometrical center. Results of PPI G3, for charge states 0 to +5 . A parabolic fit corresponding to a dense core model is displayed in dashed lines.

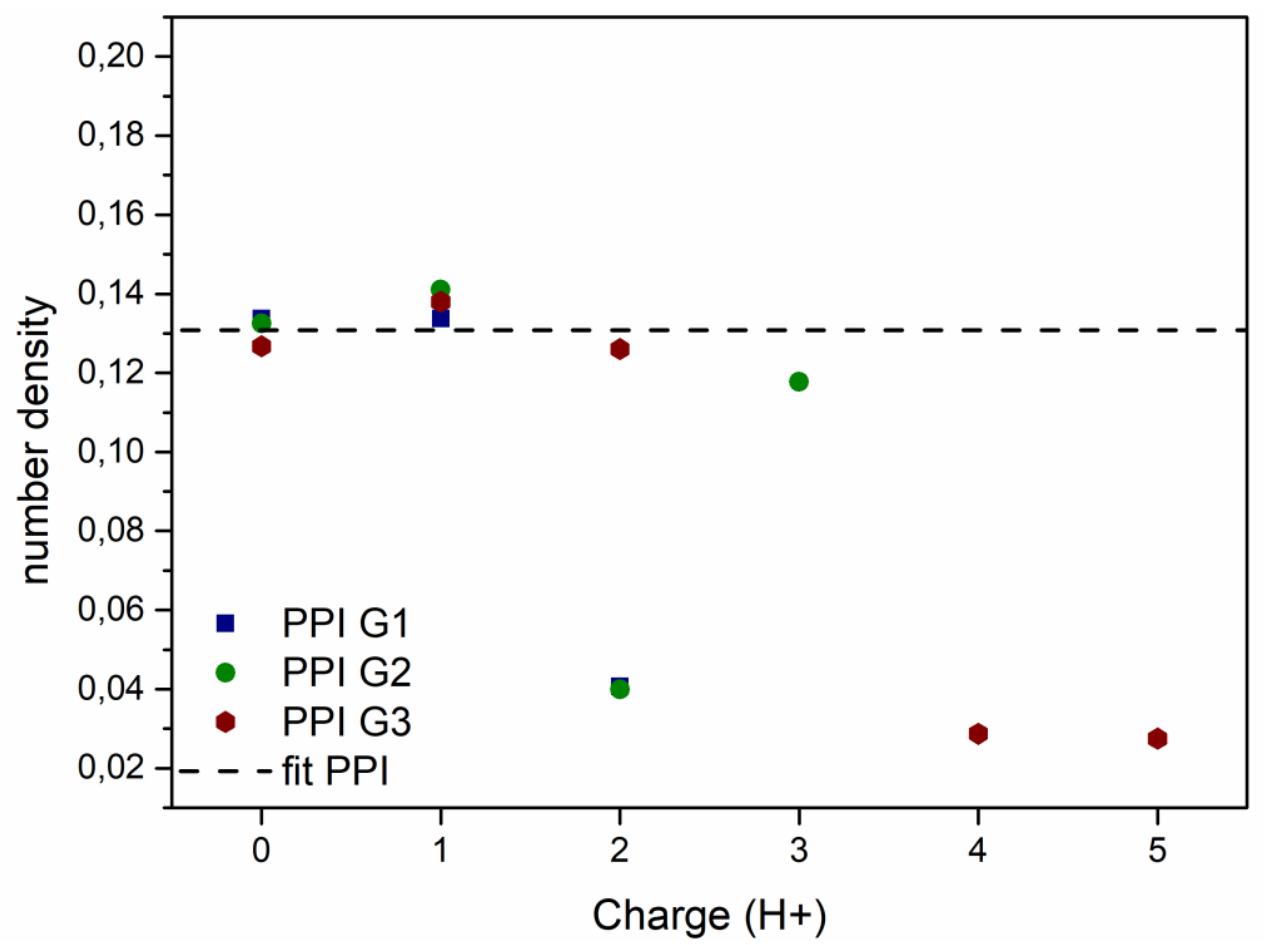

Figure S32: Number density of the dense core for PPI G1 to G3 with different charge states. The average density is represented in dash lines. 
Table S6: Comparison between SASA density and apparent density for lowest charge state PPI ions

\begin{tabular}{|l|l|l|l|}
\hline \multicolumn{4}{|l|}{ PPI } \\
\hline$G_{x}$ & Charge & $\rho$ CCS $\left(\mathrm{Da} / \AA^{3}\right)$ & $\rho$ SASA $\left(\mathrm{Da} / \AA^{3}\right)$ \\
\hline $\mathrm{G} 1$ & +1 & 0.33 & 0.32 \\
\hline $\mathrm{G} 2$ & +1 & 0.30 & 0.36 \\
\hline $\mathrm{G} 3$ & +2 & 0.30 & 0.40 \\
\hline
\end{tabular}

\section{Equations development}

For a sphere with a radius $\mathrm{R}$, a mass $\mathrm{M}$ and a density $\rho$ :

$$
\begin{gathered}
\mathrm{CCS}=\pi \mathrm{R}^{2} \text { and } \mathrm{V}=\frac{4 \pi \mathrm{R}^{3}}{3}=\frac{\mathrm{M}}{\rho} \\
\mathrm{R}=\sqrt[3]{\frac{3 \mathrm{M}}{4 \pi \rho}} \\
\mathrm{CCS}=\pi\left(\frac{3 \mathrm{M}}{4 \pi \rho}\right)^{2 / 3} \\
\mathrm{CCS}=\left(\frac{3 \sqrt{\pi}}{4 \rho}\right)^{2 / 3} \mathrm{M}^{2 / 3}=\mathrm{A} \mathrm{M}^{2 / 3} \text { (Equation 2) } \\
\mathrm{A}=\left(\frac{3 \sqrt{\pi}}{4 \rho}\right)^{2 / 3} \\
\mathrm{~A}^{3 / 2}=\frac{3 \sqrt{\pi}}{4 \rho} \\
\rho=\frac{3}{4} \sqrt{\frac{\pi}{\mathrm{A}^{3}}} \quad(\text { Equation 3) }
\end{gathered}
$$

Parabolic fitting of RDF:

$$
\mathrm{N}(\mathrm{R} \rightarrow \mathrm{R}+\Delta \mathrm{R})=\mathrm{nV}(\mathrm{R} \rightarrow \mathrm{R}+\Delta \mathrm{R})(\text { Equation } 4)
$$

The volume $(\mathrm{V})$ of a spherical shell between $\mathrm{R}$ and $\mathrm{R}+\Delta \mathrm{R}$ is the difference between the volume of the sphere of radius $R+\Delta R$ and the inner sphere of radius $R$ as given by:

$$
\begin{gathered}
\mathrm{V}(\mathrm{R} \rightarrow \mathrm{R}+\Delta \mathrm{R})=\frac{4 \pi}{3}(\mathrm{R}+\Delta \mathrm{R})^{3}-\frac{4 \pi}{3} \mathrm{R}^{3} \\
\mathrm{~V}(\mathrm{R} \rightarrow \mathrm{R}+\Delta \mathrm{R})=\frac{4 \pi}{3}\left(3 \mathrm{R}^{2} \Delta \mathrm{R}+3 \mathrm{R}(\Delta \mathrm{R})^{2}+(\Delta \mathrm{R})^{3}\right)
\end{gathered}
$$

In our calculations, the shell thickness is set at $0.1 \AA$, so $\Delta \mathrm{R}$ can be replaced by 0.1 to give:

$$
\mathrm{V}(\mathrm{R} \rightarrow \mathrm{R}+\Delta \mathrm{R})=4 \pi\left(0.1 \mathrm{R}^{2}+0.01 \mathrm{R}+\frac{0.001}{3}\right)
$$

This equation together with equation 4 give the evolution of the number of atoms as a function of the distance for a homogeneous sphere.

$$
\mathrm{N}(\mathrm{R} \rightarrow \mathrm{R}+\Delta \mathrm{R})=\mathrm{n} 4 \pi\left(0.1 \mathrm{R}^{2}+0.01 \mathrm{R}+\frac{0.001}{3}\right)(\text { Equation } 5)
$$




\section{Ion mobility parameters}

Table S7: TWIMS parameters for PAMAM G0 and PPI G1

\begin{tabular}{|l|l|l|l|l|}
\hline Set & Mass range & IMS Gas Flow (mL.min $\left.{ }^{-1}\right)$ & IMS Wave Velocity $\left(\mathbf{m} \mathbf{s}^{-\mathbf{1}}\right)$ & IMS Wave Height (V) \\
\hline $\mathbf{1}$ & $100-4000$ & 95 & 950 & 40 \\
\hline $\mathbf{2}$ & $100-4000$ & 75 & 800 & 40 \\
\hline $\mathbf{3}$ & $100-4000$ & 70 & 850 & 40 \\
\hline $\mathbf{4}$ & $100-2000$ & 85 & 900 & 40 \\
\hline $\mathbf{5}$ & $100-2000$ & 80 & 800 & 40 \\
\hline
\end{tabular}

Table S8: TWIMS parameters for other ions

\begin{tabular}{|c|c|c|c|c|}
\hline Set & Mass range & IMS Gas Flow (mL.min $\left.{ }^{-1}\right)$ & IMS Wave Velocity $\left(\mathrm{m}^{-\mathrm{s}^{-1}}\right)$ & IMS Wave Height (V) \\
\hline 1 & $100-4000$ & 75 & 800 & 40 \\
\hline 2 & $100-4000$ & 70 & 850 & 40 \\
\hline 3 & $100-2000$ & 60 & 650 & 40 \\
\hline
\end{tabular}

\section{DRIFT TUBE EXPERIMENTS}

${ }^{\mathrm{DT}} \mathrm{CCS}_{\mathrm{He}}$ are measured using a custom DTIMS instrument described elsewhere ${ }^{2,3}$. The drift tube measures $79 \mathrm{~cm}$ and is filled with a constant helium pressure of 5.1 Torr at $295 \mathrm{~K}$. Spectra are recorded with voltage between 200 and 600 V.

\section{REFERENCES}

(1) Giordanengo, R.; Mazarin, M.; Wu, J.; Peng, L.; Charles, L. Propagation of Structural Deviations of Poly(Amidoamine) Fan-Shape Dendrimers (Generations 0-3) Characterized by MALDI and Electrospray Mass Spectrometry. Int. J. Mass Spectrom. 2007, 266 (13), 62-75.

(2) Simon, A. L.; Chirot, F.; Choi, C. M.; Clavier, C.; Barbaire, M.; Maurelli, J.; Dagany, X.; MacAleese, L.; Dugourd, P. Tandem Ion Mobility Spectrometry Coupled to Laser Excitation. Rev. Sci. Instrum. 2015, 86 (9).

(3) Choi, C. M.; Simon, A.; Chirot, F.; Kulesza, A.; Knight, G.; Daly, S.; MacAleese, L.; Antoine, R.; Dugourd, P. Charge, Color, and Conformation: Spectroscopy on Isomer-Selected Peptide Ions. J. Phys. Chem. B 2016, 120 (4), 709-714. 